\title{
Deep Personalization For Better Human Connect And Optimization By Using Non-Conventional Mechanisms In The Modern Digital Systems
}

\author{
Raghav Sehgal, \\ Assisted Sales, Verizon, Chennai, India \\ DOI: 10.29322/IJSRP.11.01.2021.p10952 \\ http://dx.doi.org/10.29322/IJSRP.11.01.2021.p10952
}

\begin{abstract}
Deep personalization is the need of the hour in today's digital sales systems. To optimize humanization within our sales funnels, sales channels and throughout the sales cycle, every organization needs to enhance the existing systems. The changes need to be brought into the user interface- such as customized landing pages, personalized product recommendations, global search, specific segmentation of customer based upon brand preference and customer needs. It has been observed by Nosto.com that a personalized web app experience generates approximately 1.3 times higher conversion rates, $18 \%$ higher average order amount as well as on an average two times increase in the customer time spent online. Most of our systems are not utilizing the data analytics in an efficient manner. While we focus on the historical transactional data, a better solution would be to change the page dynamically using behavioral data, which accounts for about $98 \%$ of data captured online and remains untouched (according to Nosto.com). An organization's emails need to be targeted and segmented based on user value, their time zone and date of purchase. Creating user communities, gamifying reward programs and referrals are other ways to establish the personalization brand of an organization. Social media dynamic ad campaigns need to be targeted using user generated content along with reviews which according to Yotpo.com would give a $62 \%$ increased return on ad spend. Care can also be shown by using feedback and negative feedback to our advantage.All these factors can help to establish any organization as a person-centric Brand and help in increasing the revenues by focusing more on repeat customers who spend 67\% more than one time shoppers on an average, (according to business.com experts) ,thus establishing regular cohorts. This paper thus lists the best modern personalization practices, which can be adopted by anyone to boost their sales.
\end{abstract}

Keywords-personalization, optimization, user-generated content, email, funnel, reward, feedback, e-commerce, digital marketing

\section{INTRODUCTION}

In today's era, the most successful organizations are those who focus on deep personalization to achieve their sales goals. With so much investment going into the use of $\mathrm{AI}$ in digital systems, a personalized user interaction makes perfect sense. This personalization is required not only when a user opens the website for the first time, but also when he/she leaves the cart incomplete. According to world's leading ecommerce personalization platform Nosto.com, it has been observed that a personalized web app experience generates approximately 1.3 times higher conversion rates, $18 \%$ higher average order amount as well as on an average two times increase in the customer time spent online. As organizations become technically sounder, personalization in all spheres becomes the need of the hour. Various avenues where such personalization can be achieved has been summed up as below:-

(a) Personalized User interface (b) Personalized emails

(c) Brand user communities (d) Referrals (e) Personalized reward programs (f) Personalized advertisements (g) Use of feedback (h) Readily visible support

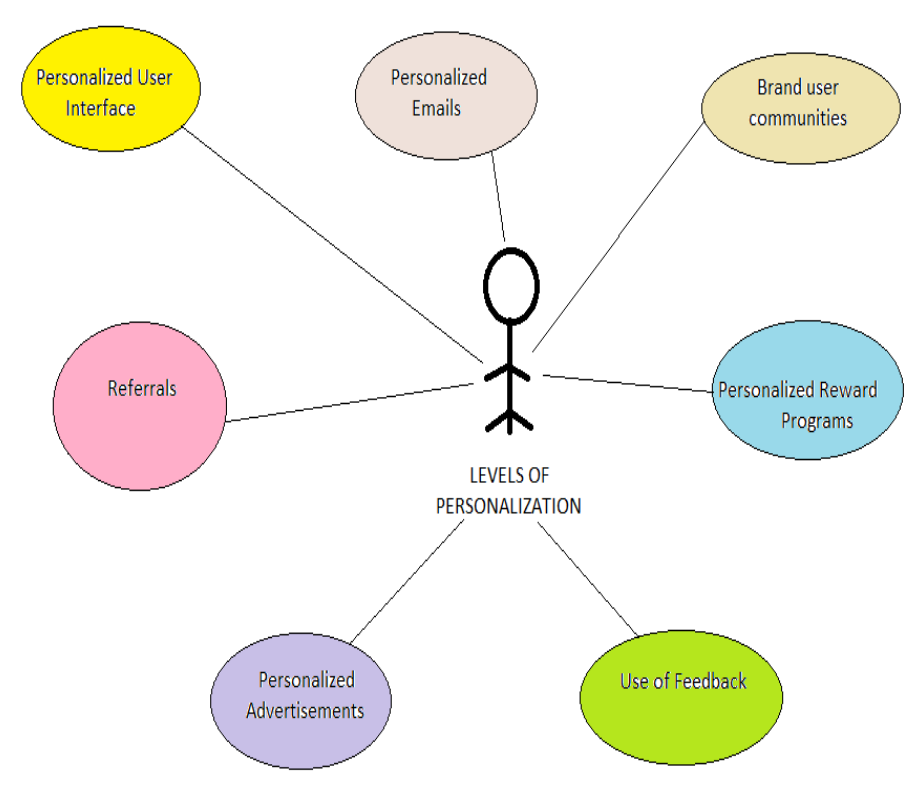

Fig I- Levels of Personalization

\section{PERSONALIZED USER INTERFACE}

According to www.eMarketer.com's report of July 2018, today Amazon has nearly 50\% of all retail e-commerce sales in the United States. This amazing success can be attributed to not only their Omni channel experience but also their personalized user interface across all platforms. For effective personalization we need to analyze not only the 
Transactional data (historical data) which according to Nosto.com's research, accounts for only $1.6 \%$ of the data captured online but also the behavioral data which is approximately $98 \%$ of the data captured. This data is the one that we need for the shopper's real-time intention and buying patterns.

\section{A. Customized landing pages}

It has been observed through Nosto.com's findings that a personalized web app experience generates approximately 1.3 times higher conversion rates, $18 \%$ higher average order amount as well as on an average two times increase in the customer time spent online. Considering this, a customized landing page is the need of the hour. A landing page should be completely dynamic. This means that for an old customer, the landing page should reflect their brand preference and for the current customer their brand preference and category affinity should be predicted real time and changed accordingly. For instance, different landing pages can be constructed for people who prefer Apple or Samsung. With people preferring videos more, it is also another good idea to have more videos on the homepage conveying info on your products. Another good example is Adobe.com. This is what the first time visit on their page looked like-

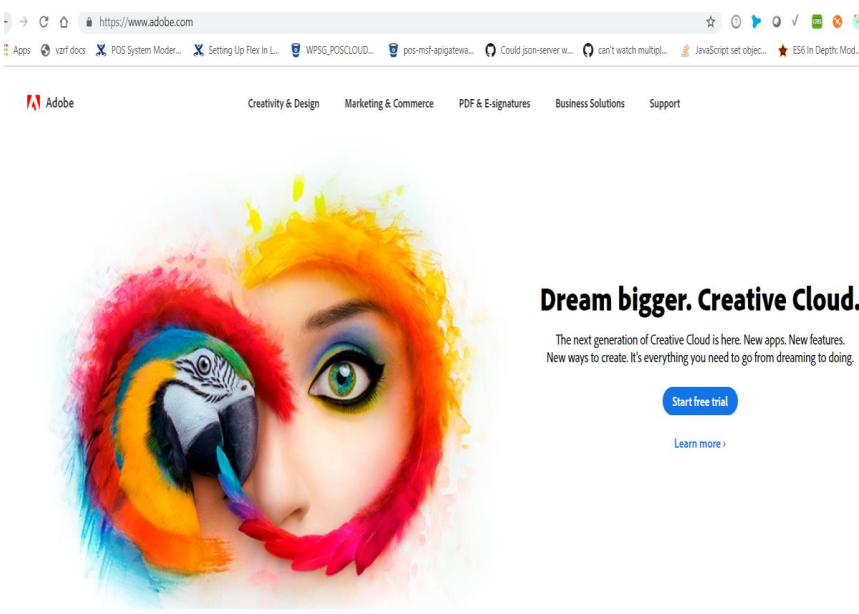

Fig II-Adobe Homepage

From Marketing \& Commerce Menu I chose Adobe Experience platform, and then closed the tab. On visiting adobe.com the second time, the homepage changed, based on my search-

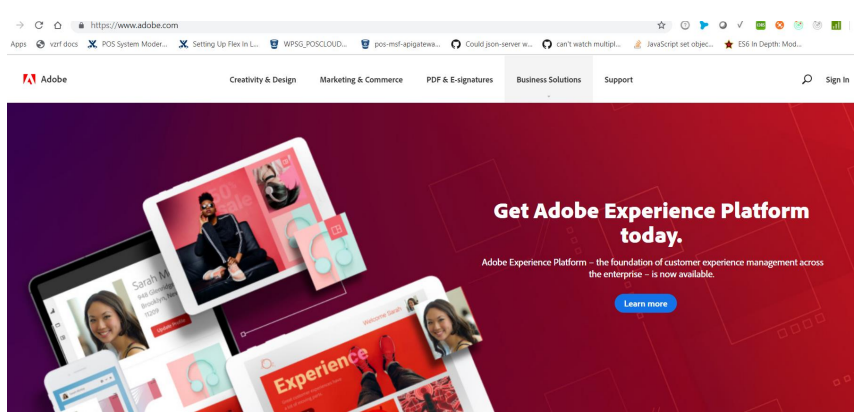

Fig III- Adobe Homepage Revisit
Landing pages can also be varied based on geographical locations. Both Amazon and Youtube are good examples for this. Adobe also considers the location for load of the homepage, giving a choice to load regional site which in my case is https://www.adobe.com/in/.

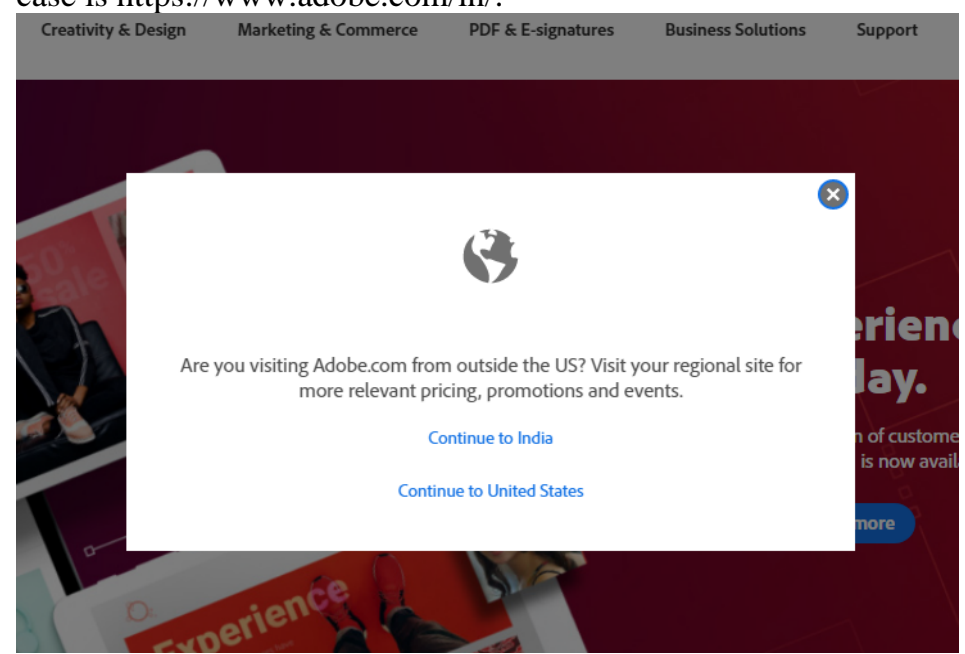

Fig IV-Adobe Regional Popup Message

Companies such as Sprint are even offering select discounts for the product $2^{\text {nd }}$ time visitors were thinking of buying:

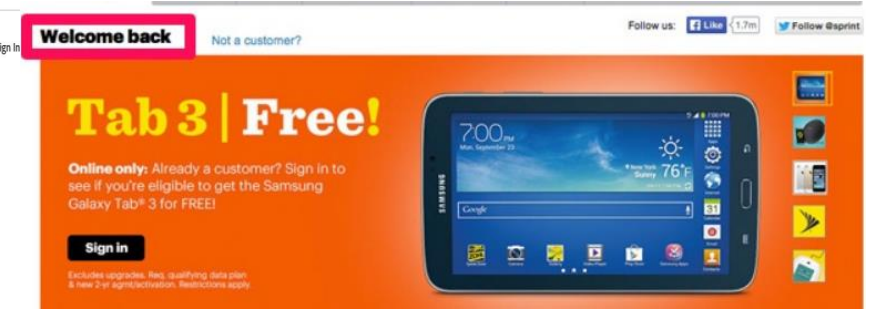

Fig V-Sprint old website with cookie based welcome back message

\section{B. Global Search}

Search can be used by user to reach a particular page that a user feels exists or that he has visited in the past. This could be at a specific point within a sales funnel. The top searches can be included in the search bar. Also, the misses can be used to add the missing pages or products that a user is looking for, later. A good practice is to expedite user search using javascript based auto-suggestion overlay. Machine learning can also be incorporated with the search to result in optimum ordering of products upfront, based on which product performs the best in realtime. According to Klevu.com's (an ecommerce site search solution) research, analysis of 869 online stores' $\$ 1.4 \mathrm{~B}$ of total online trade (over a 7 month period) showed that over $\$ 360 \mathrm{M}$ of this ( $27 \%$ of the total recorded business) directly came from the site search.

\section{User Segmentation}

User segmentation upfront helps to target specific users for a personalized experience. Segmentation can be done based on new or VIP customer. This can help to identify when and whom to offer discount. Customer brand preference is another factor which will determine segmentation. Once done, the UI experience will vary for different customer 
type. For example, for a mobile store, UI experience can be varied based on Apple or Google brand preference.

\section{Personalized Product Recommendation}

Best example of this is Amazon which shows the items that customers bought along with the items added to cart: customers Who Bought This Item Also Bought

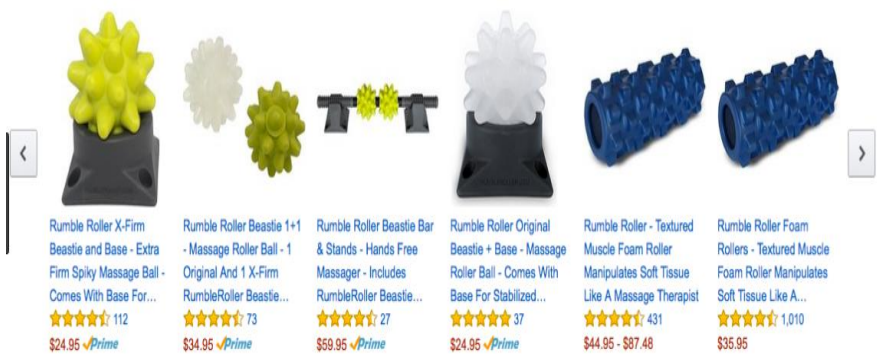

Fig VI- Amazon.com product recommendation

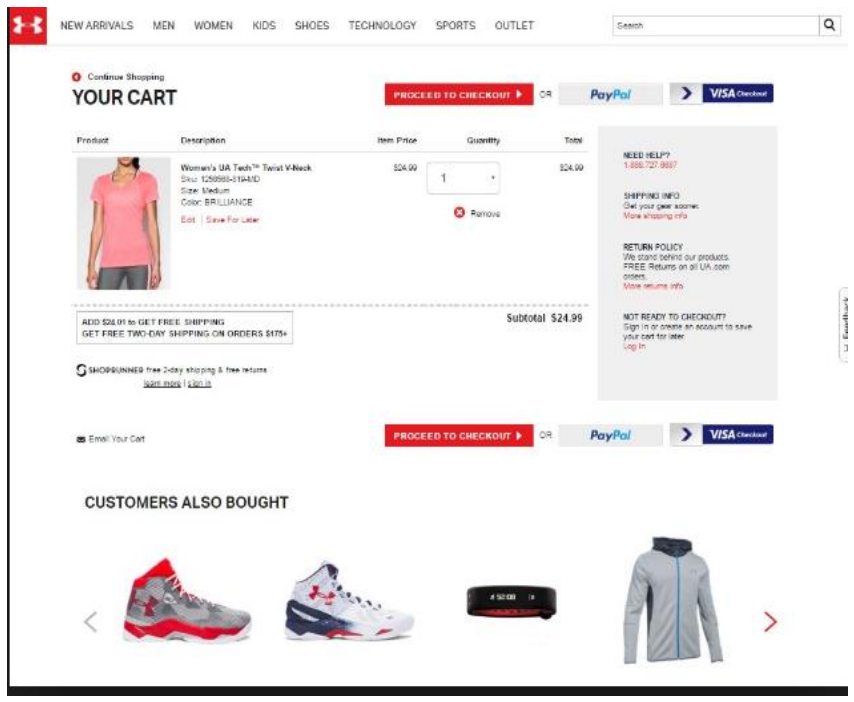

Fig VII- Cross selling through 'customers also bought'

The above is an example of cross selling that can be added just below the cart items view and also just below the Product Display Page section to enhance UX and boost sales.

\section{E. Reviews on product display pages}

Users must first be prompted to write reviews about the products, which can be done both onsite as well as by sending emails using AI to detect the topics that are most popular among the users as well as after they buy it each time. Customer reviews, photos, and Q\&A should be showcased on your homepage, category pages, product pages, social ads, email marketing- in short everywhere. Using user generated content can increase the ecommerce conversion rate by about $161 \%$ according to yotpo.com, which analyzed 200,000 eCommerce stores where visitors were actively engaging with customer reviews, star ratings, and customer photos. Yotpo team also found that on average, $55 \%$ of customers engage with user generated content before making a purchase. UNTUCKit, a clothing brand on Shopify does just that.

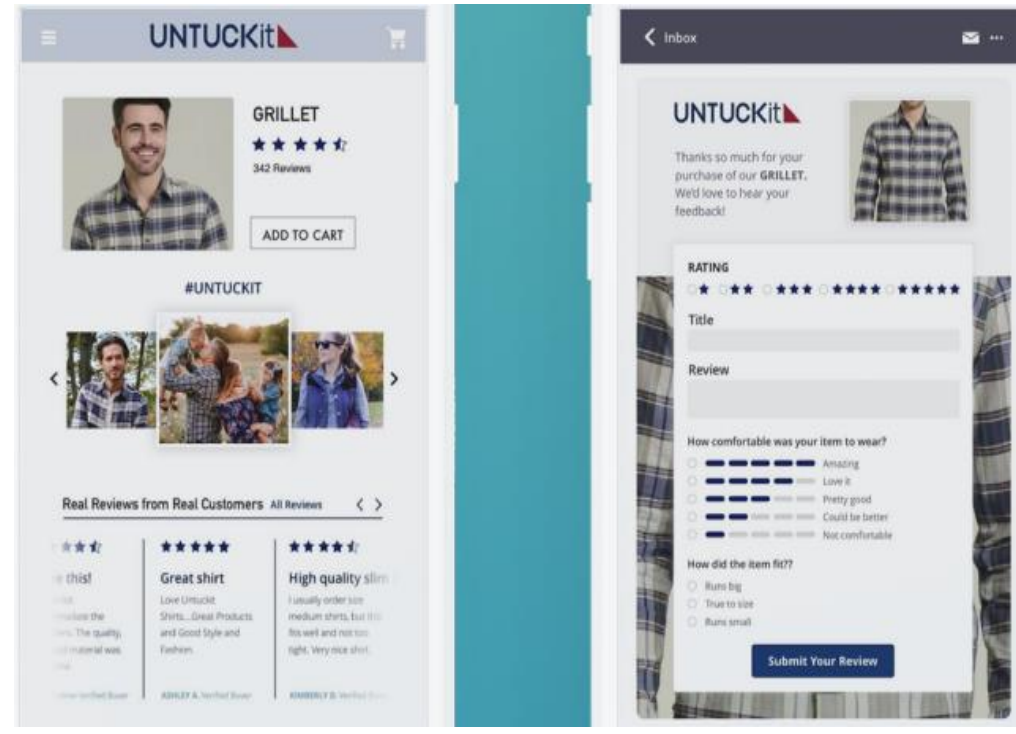

Fig VIII- UNTUCKit product display page

\section{PERSONALIZED EMAILS}

Personalization in the emails is of utmost essence. It makes the users feel that certain connect and care. Any new subscriber must always be greeted with a Welcome and Thank you message. Care must be taken to send the message to only those who have opted for the email service. Also, they must be invited to tell you how often they'd like to hear from you. The subscription to email service can be done upfront on the website through a popup.

\section{F. Timing}

Timing for the email is very crucial. The send time for any email must always be focused on the time zone. Engagement data needs to be collected to create a sending schedule based on how engaged a reader is. The more engaged clients need to be sent messages more often. Similarly, promotional messages must not be sent to recent purchasers since it would be better to send them to those who are not very frequent buyers.

\section{G. Cart/Session Recovery}

An effective strategy for capitalizing on sales is the browse recovery email. For this any data that a user is browsing needs to be constantly tracked. Users who viewed a certain product within a specific timespan need to be targeted by sending mails. This can also be done by sending email if the total number of qualifying items within a certain category is exceeded. When the user abandons a cart after adding items to it, a transactional email can be sent giving them a direct link to recover the cart- giving them indirect reasons to buy such as warranty details, similar product recommendations, shipping policy, store contact information, 'last chance' urgency etc. The best example of this is Udemy website which sends a regular email to users who browsed certain items, even providing them similar courses to choose from which open at direct links. 


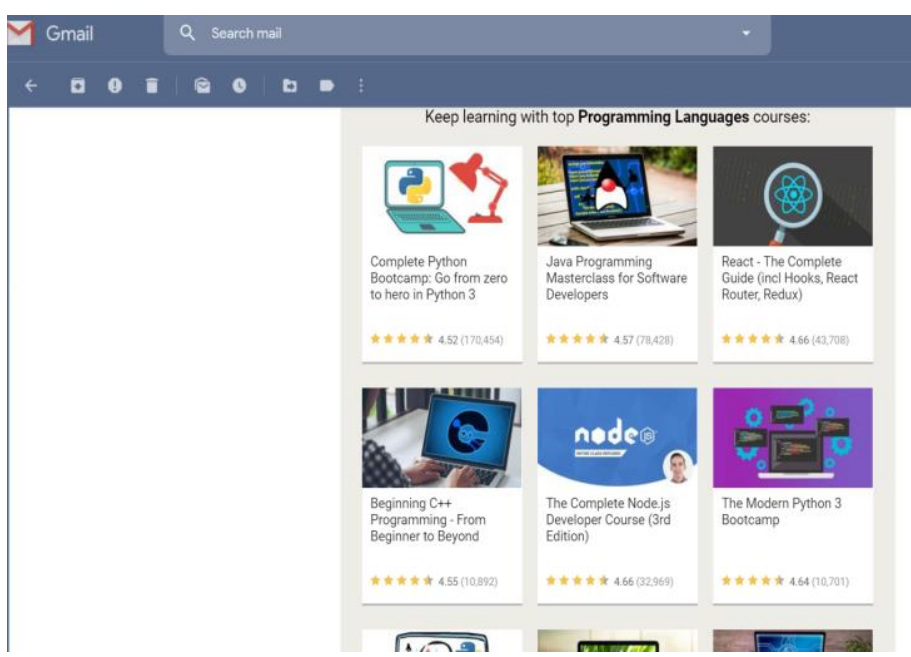

Fig IX-Udemy personalized emails

Here's another example of mail by rrjewels.com:

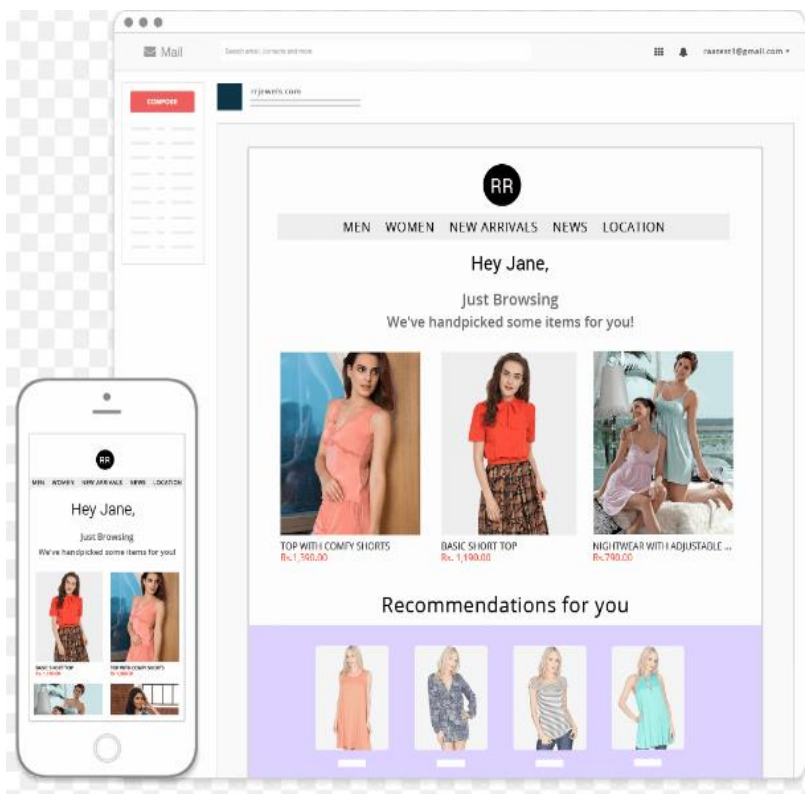

Fig $X$-Rrjewels email

\section{H. Email Button}

It is a very good idea to include a separate section of Browse History within the application and to include an email button which will enable the users to mail the browse history to themselves for reference later. Auto-mail should only be triggered to the subscribers.

\section{BRAND USER COMMUNITIES}

A lot of brands have started online communities and forums to make customers feel connected and valued. Sephora brand has started a 'Beauty talk' online forum where user can ask questions, share ideas and get all their beauty queries solved through experts. They even have a 'Beauty Board' where users upload a picture of themselves wearing Sephora products. The photos are linked to the product page of all the items used. This ensures that those browsing can directly buy items and also upload their style preferences influencing others.

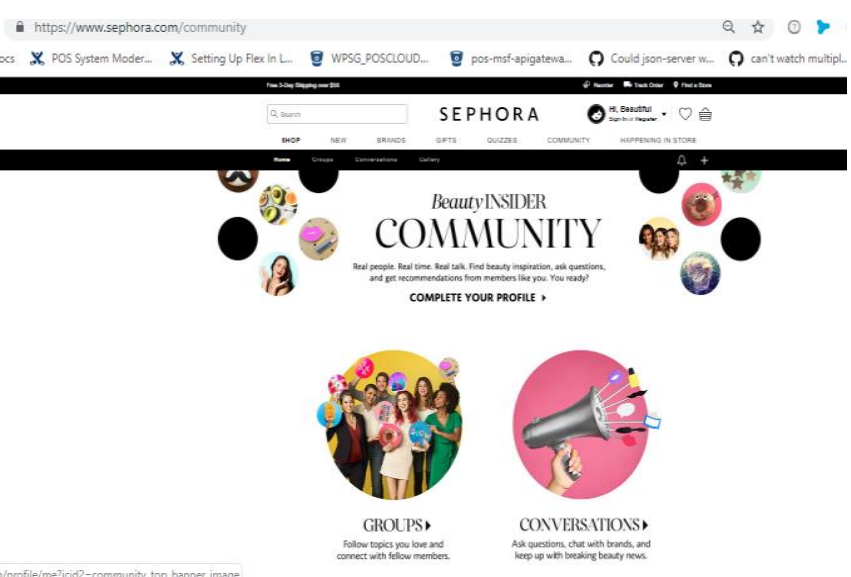

Fig XI- Sephora discussion forum

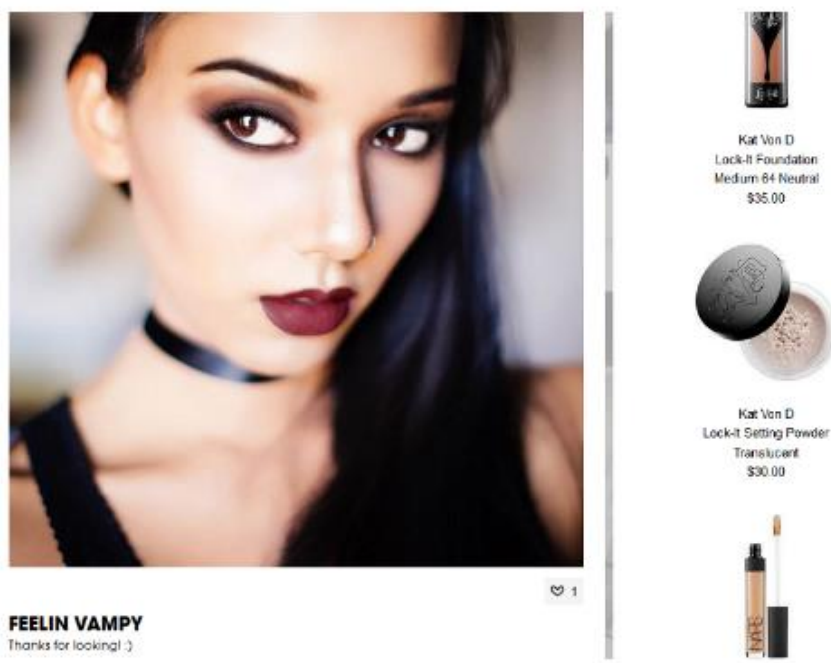

Fig XII-Sephora beauty board

Brands such as Strabucks empowered customers through forum like 'My Starbucks Idea'. People could browse through other ideas, cast their vote and share feedback.This made the customer feel valued and the brand could leverage their strategies according to the customer preference- a total win win. Although the forum has now retired but it was very advantageous for Starbucks. To create such forums people can be motivated through monetary benefits or recognition or both. Strict community guidelines would ensure less of monitoring for the moderators on the platform.

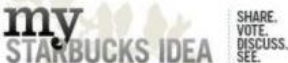

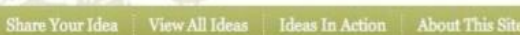

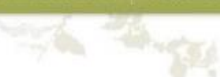

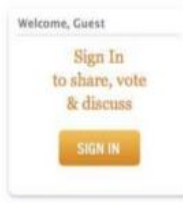

Check out

the latest

ideas now!

\section{Help shape the future of Starbucks - with your ideas}

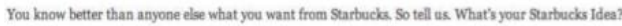
Reolutionary or simple-we want to hear it Share gour ideas tell us what you think of other peoplest

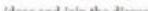
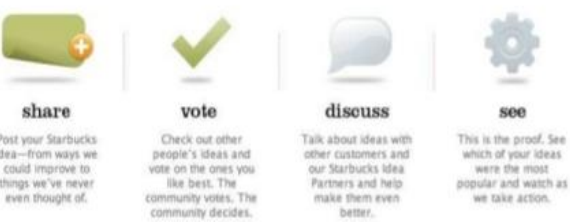

Fig XIII- My Starbucks Idea 


\section{REFERRALS}

Currently this is one of the most effective strategies to build your brand niche, community and boosting sales at the same time. One plus brand created a referral program of exclusivity and demand where they had an invite only system for the phone. This all made the phone talked about more. They still use it to create hype before a big flagship launch. Another important thing to note is that any referral offer must be highlighted upfront on the website homepage so that the users can connect to it directly and it leverages personalization effectively. According to Nielsen's Harris Poll of 2016 in which 2000 Americans were surveyed online, it was found that $82 \%$ of people actively seek referrals before making a purchase as it builds trust. Food brand Veestro has a good referral program where every person who refers gets a $\$ 35$ discount coupon which can be redeemed later.
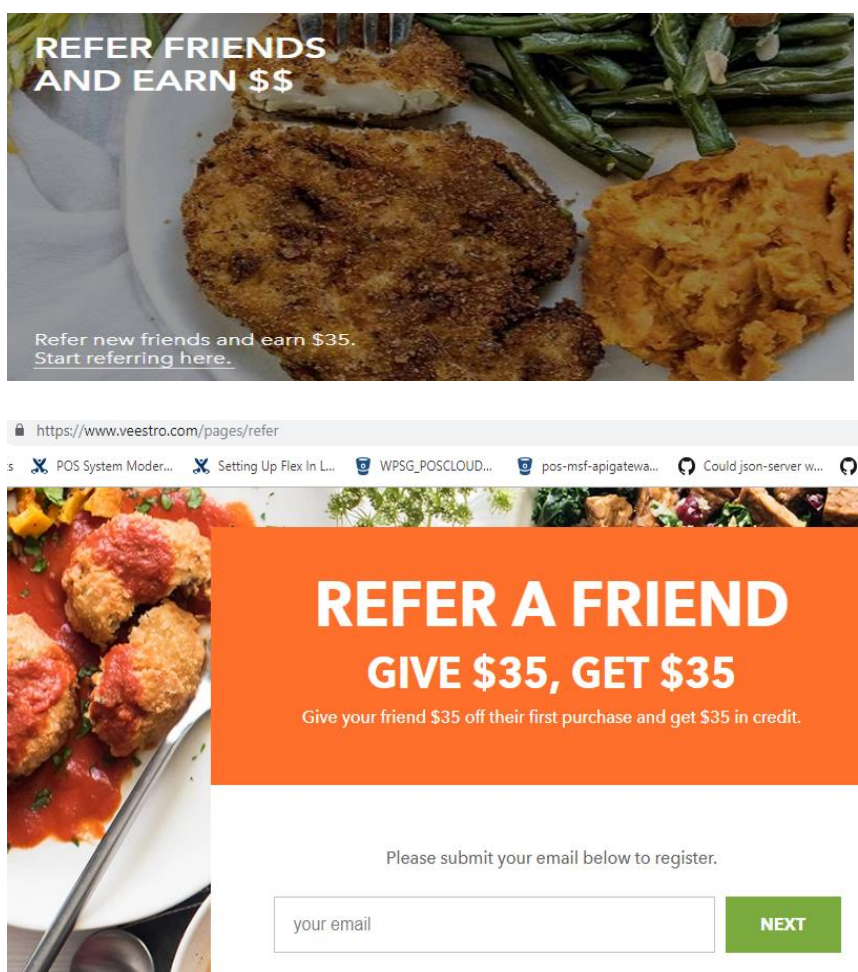

Fig XIV-Veestro refer a friend

\section{PERSONALIZED REWARd PROGRAMS}

It is a well-known fact that a companies' health and long term growth is linked to existing customers. Here are a few customer retention stats collected from small scale businesses by 'smallbiztrends.com':

- 65 percent of a company’s business comes from existing customers.

- The probability of selling to an existing customer is $60-70$ percent. The probability of selling to a new client is 5-20 percent.

- 80 percent of your future profits will come from just 20 percent of your existing customers.

- It costs 5 percent more to acquire a new customer than it does to keep a current one.
- A mere two percent increase in customer retention can lower costs by as much as 10 percent.

- It costs 16x more to bring a new customer up to the same level as a current one.

- A five percent increase in customer retention can lead to an increase in profits of between 25 and 95 percent.

The reward programs thus become crucial for retaining the existing customers. They make a customer feel that they belong. An effective way to carry out this is not just by using points and monetary reward strategy but also by triggering emotions and feelings in the buyers through some dedicated cause which is highlighted upfront on the homepage. 'Hey Girls' brand has created its own organic sanitary products and ensures that when one sanitary pad is bought, another one is donated to those in need.

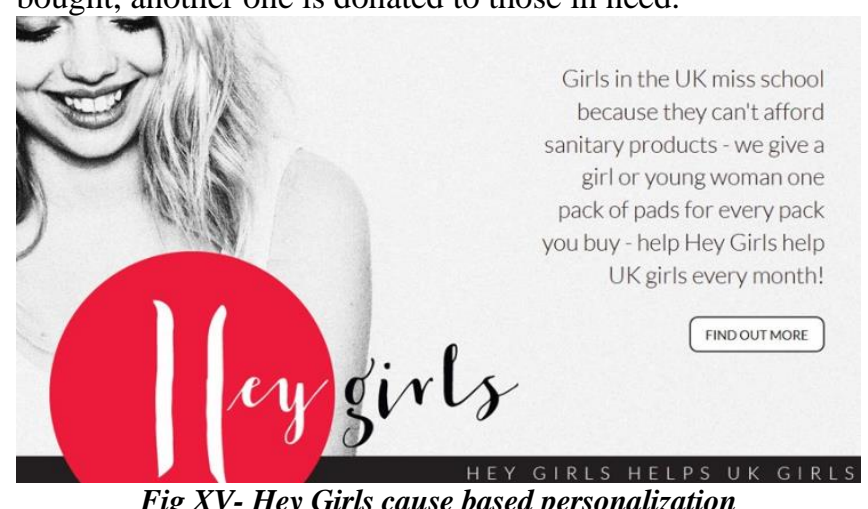

Even Verizon has an effective page dedicated to military wherein special plans as well as career opportunities are exclusively available to those who are a part of the military.

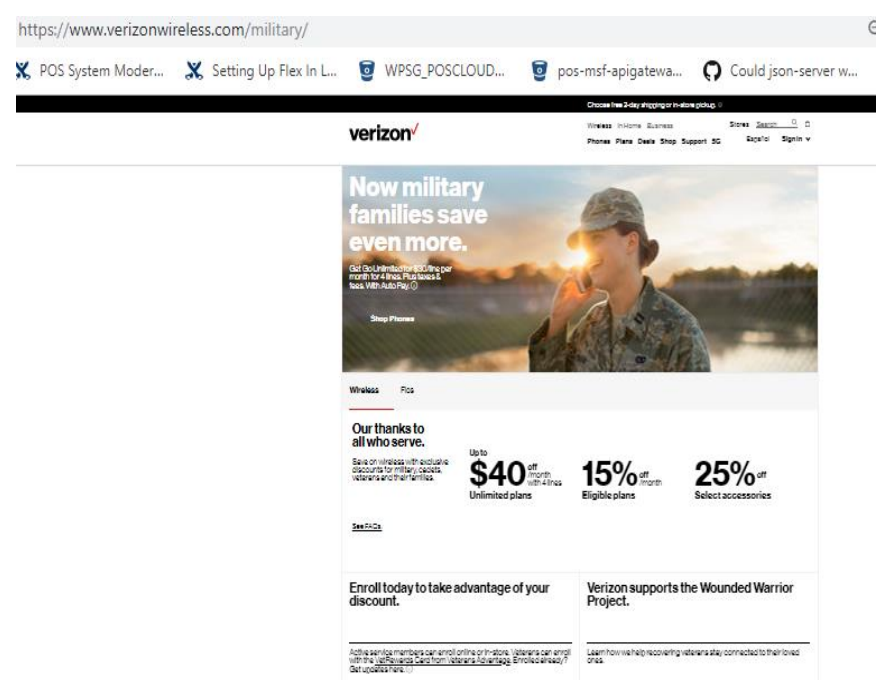

Fig XVI- Verizon military based cause

The key idea here would be to ensure that such facts are highlighted upfront on the website homepage itself. 
Reward programs can be based on points which can later be converted to discounts. Again Veestro has a dedicated page for the rewards clearly highlighting this aspect.

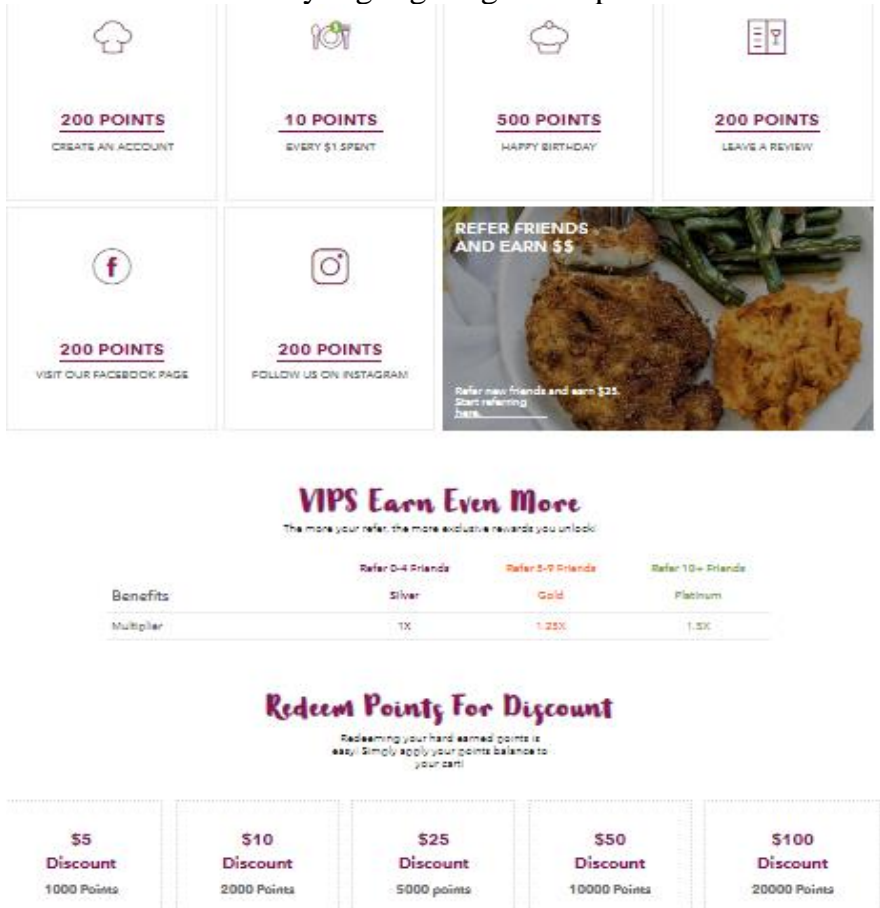

Fig XVII- Veestro Reward programme

But, again any such reward program needs to be clearly highlighted on the homepage as done here by last season clothing brand:
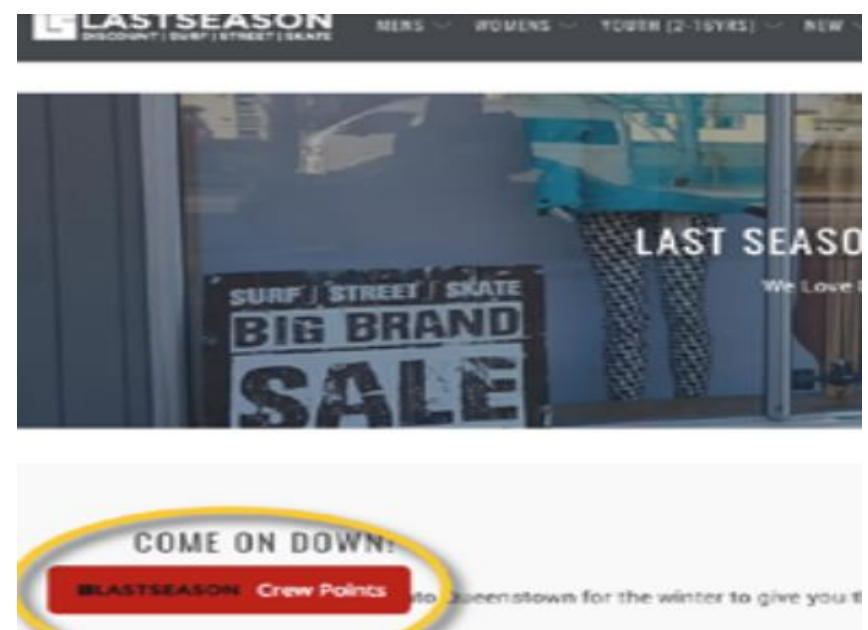

Fig XVIII- Last season reward program link on homepage

\section{PERSONALIZED ADVERTISEMENTS}

Most of the marketing being done online is being carried out on social media currently. Machine learning can help brands to advertise the product that they were keen on buying. But, here's the catch. How do we ensure that the product which they did not buy the last time, gets more leverage? We can do that by adding User Generated Content to create dynamic ads on social media. This is done by showing a relevant photograph of the product along with its best customer reviews and also the star marked rating of the product to add in personalization effect. According to Yotpo.com's
Blenders Eyewear case study, Ads along with user generated content can lead to a $38 \%$ decrease in cost per acquisition, and $62 \%$ increase returns on ad spend. Here's what a successful ad would look like:

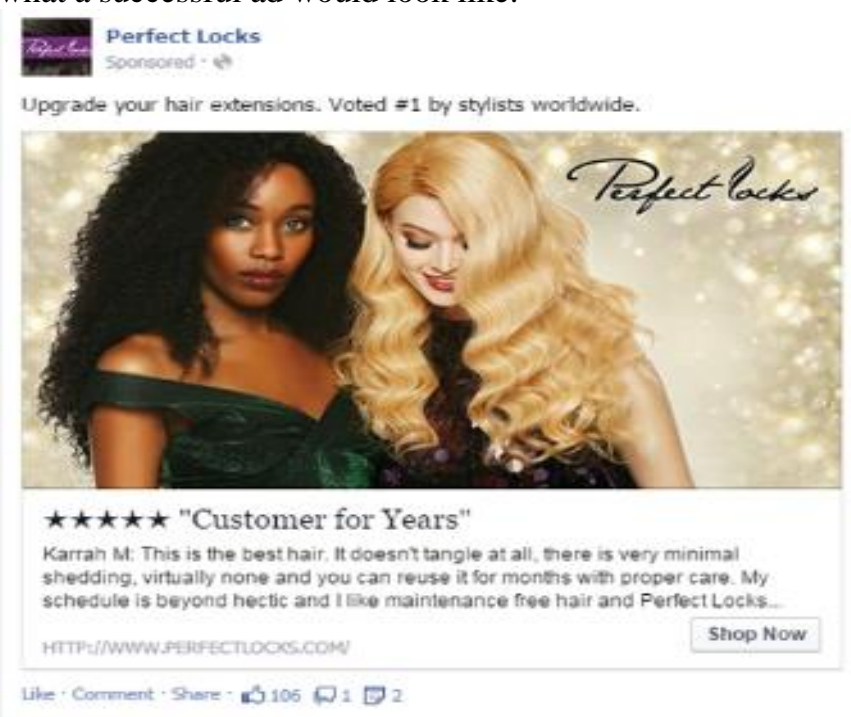

Fig XIX-PerfectLocks user generated content + star ratings advertisement

\section{USE OF FEEDBACK}

Brands should leverage not only positive but also negative feedback to their advantage. Showing negative feedback along with positive on the website ensures trust and genuineness. One effective way to collect feedback is by asking it right after a purchase is made on the order completion screen. 


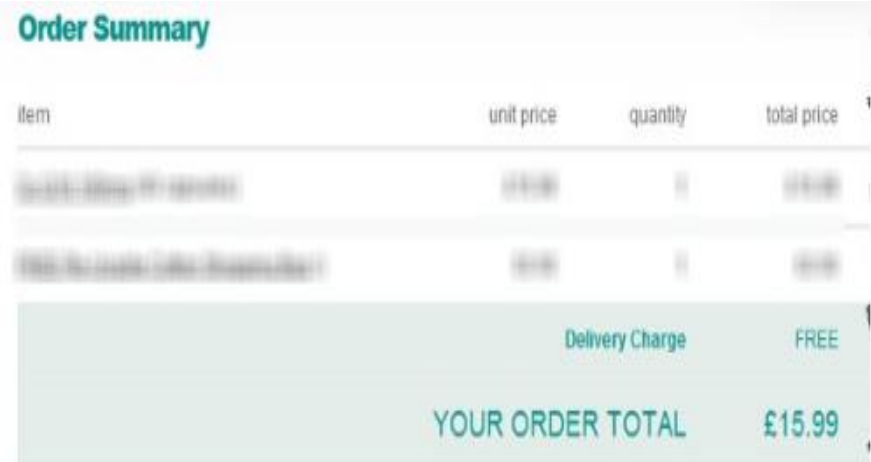

Thank you for shopping with us. If you have a moment, we'd welcome some feedback.

1. Pease read through the followng questons and rate us accordingly

How easy was t to find what you wanted?
How would you rate the varitly of products avaliable from us?
Overal, how would you rate your experience shopping on
2. How lkely are you to recommend us to others?
Very Lkey Somewhat Likey Nemer likey or unikely Somewhat unikey Very unikety

3. Any futher comments?

Fig XX-Feedback form on order completion screen

Feedback should immediately be taken as soon as a user tries to abandon the cart. 'Ola Cabs' does it as soon as a ride is cancelled asking the reason. Another example is:

is cancelled asking the reason. Another example

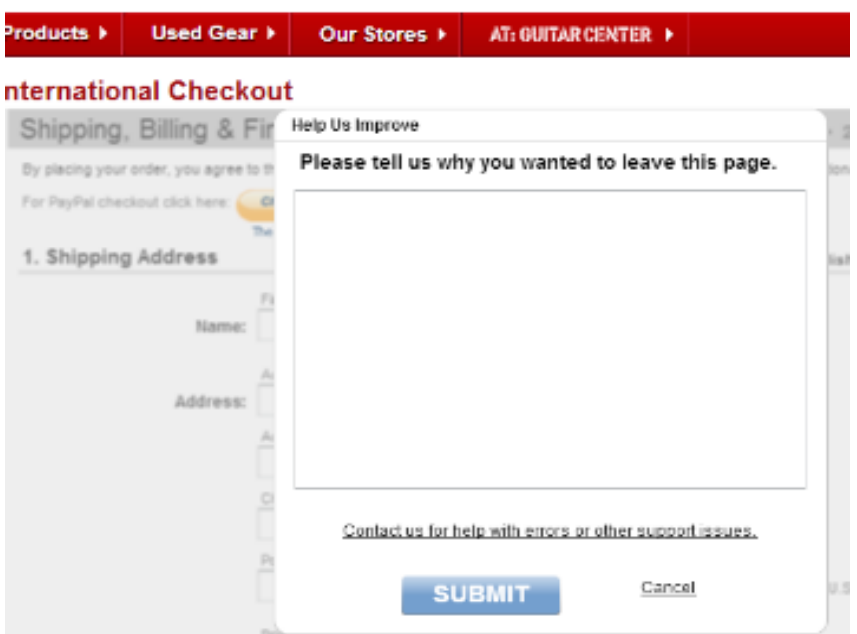

Fig XXI- Feedback form on leaving any page mid funnel

A multiple choice response serves much better. Typical responses can include a) unexpected/added costs at checkout stage b) got a better deal at another site c) process taking long d) delivery options don't suit requirements, etc. Contact customer support option must be provided for sure.
READILY VISIBLE SUPPORT

Most customers want to but the product but may have some clarifications regarding it. All their doubts can be removed by first leveraging an active live chart support right at the homepage. The chat can be both automated as well as inperson. Even a feedback can be collected right after the chat. Another way to ensure that the customer is well taken care of is to have the contact number for support clearly displayed directly at the title bar of the landing page. Here's an example from Sprint's website:

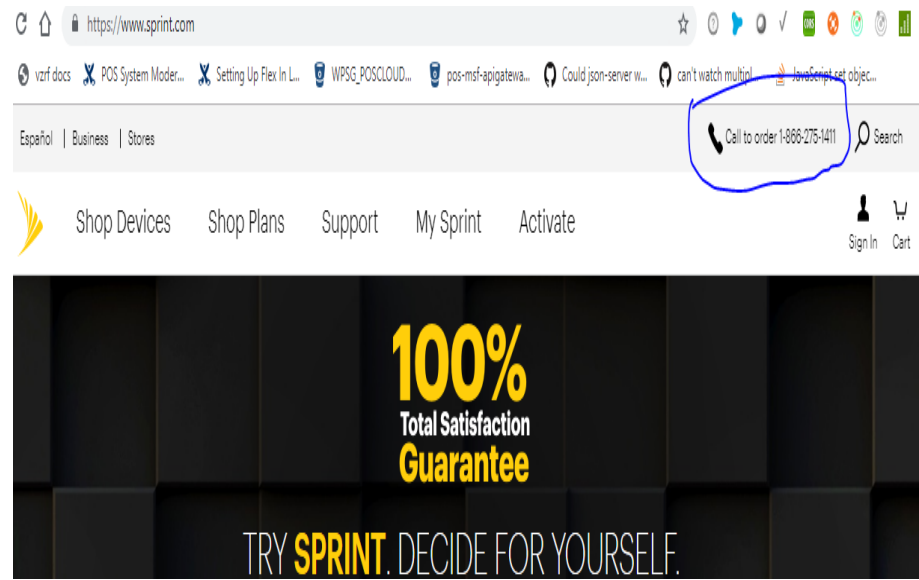

Fig XXII- Sprint contact number clearly given on homepage

They even highlight the omni-channel experience uptop clearly.

$$
\text { Support My Sprint Activate }
$$

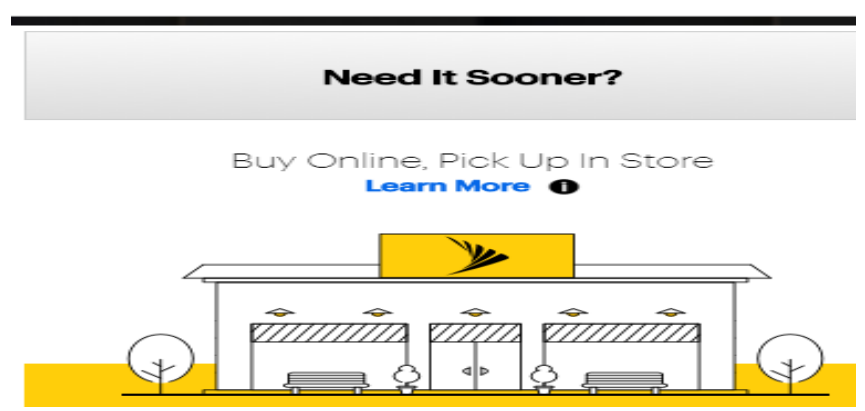

Fig XXIII- Sprint omni channel experience clearly given on homepage- online/store options

\section{CONCLUSION}

Thus, Deep personalization is extremely vital to boost sales in any organization. Once, all these strategies are followed, customer engagement can be catapulted and sales can be boosted manifolds.

\section{ACKNOWLEDGMENT}

I would like to thank my manager Rajasekaran,Victor for pointing me in the right direction and special thanks to Krishnamurthi, Kanakasubramaniam R (Assoc Dir-Sys Engrg, Verizon Consumer Group) for mentoring, guiding and helping me in finalizing the topic of research. 


\section{REFERENCES}

[1] Aimee Millwood,' The Guide To Data-0Driven User-Generated Content Marketing', Feb 19, 2017.[Online]. Available: https://www.yotpo.com/blog/data-driven-contentmarketing/?utm_source=partners\&utm_medium=nosto\&utm_campai gn=powerupplus/. [Accessed: 06-Oct-2019]

[2] Amitv Kanadia. 'Numhers Don't Lie: What a 2016 Nielsen Study Revealed About Referrals', Mar 12 2016.[Online]. Available:https://www.business2community.com/marketing/numbers -dont-lie-2016-nielsen-study-revealed-referrals-01477256/. [Accessed: 06-Oct-2019]

[3] Andrea Wahbe,'Six must have technologies to build the best ecommerce stack', Dec 2018. [Online]. Available: https://www.shopify.com/enterprise/six-must-have-technologies-tobuild-the-best-ecommerce-tech-stack\#TechStack1. [Accessed: 30Jul- 2019]

[4] 'Blenders Eyewear Mixes in Social Proof to Power Facebook Ads'.[Online]. Available: https://www.yotpo.com/casestudies/blenders/. [Accessed: 06-Oct-2019]

[5] Corey Bloom,' eCommerce Conversion Rate: The Stats That Matter', Jan 10, 2017.[Online]. Available: https://www.yotpo.com/blog/ecommerce-conversion-rate/. [Accessed: 06-Oct-2019]

[6] eMarketer articles, [Online]. Available: https://www.emarketer.com/articles/topics/retail-ecommerce/. [Accessed: 06-Oct-2019]

[7] Judit Pal,'How to get quality customer feedback-20 effective methods',Jul 232018 [Online]. Available: https://www.optimonk.com/15-ways-e-commerce-websites-getcustomer-feedback/. [Accessed: 30- Jul- 2019]
[8] Jun-Sheng-Li,'How amazon took $50 \%$ of the ecommerce market and what it means for the rest of us',Mar 2019 [Online]. Avalilable: https://techcrunch.com/2019/02/27/how-amazon-took-50-of-the-ecommerce-market-and-what-it-means-for-the-rest-of-us/.[Accessed: 30- Jul- 2019]

[9] Klevu blog. [Online]. Available: https://info.klevu.com/blog [Accessed: 06-Oct-2019]

[10] Lauren Thomas | Courtney Reagan, 'Watch out, retailers. This is just how big Amazon is becoming', July 13, 2018. [Online]. Available: https://www.cnbc.com/2018/07/12/amazon-to-take-almost-50percent-of-us-e-commerce-market-by-years-end.html/. [Accessed: 06Oct-2019]

[11] Matt Clark, 'Returning Customers Spend 67\% More Than New Customers - Keep Your Customers Coming Back with a Recurring Revenue Sales Model', May 1, 2013.[Online]. Available: https://www.business.com/articles/returning-customers-spend-67more-than-new-customers-keep-your-customers-coming-back-with-arecurring-revenue-sales-model/. [Accessed: 06-Oct-2019]

[12] Matt Mansfield, 'CUSTOMER RETENTION STATISTICS - The Ultimate Collection for Small Business', Aug 2019. [Online]. Available: https://smallbiztrends.com/2016/10/customer-retentionstatistics.html/. [Accessed: 06-Oct-2019]

[13] Neil Patel, 'The homepage is dead: How to personalize homepage to each unique visitor', 2019. [Online]. Available: https://neilpatel.com/blog/personalize-website-pages/

[14] Nosto blog. [Online]. Available: https://www.nosto.com/blog/ [Accessed: 06-Oct-2019] 
FIGURES AND IMAGES USED:

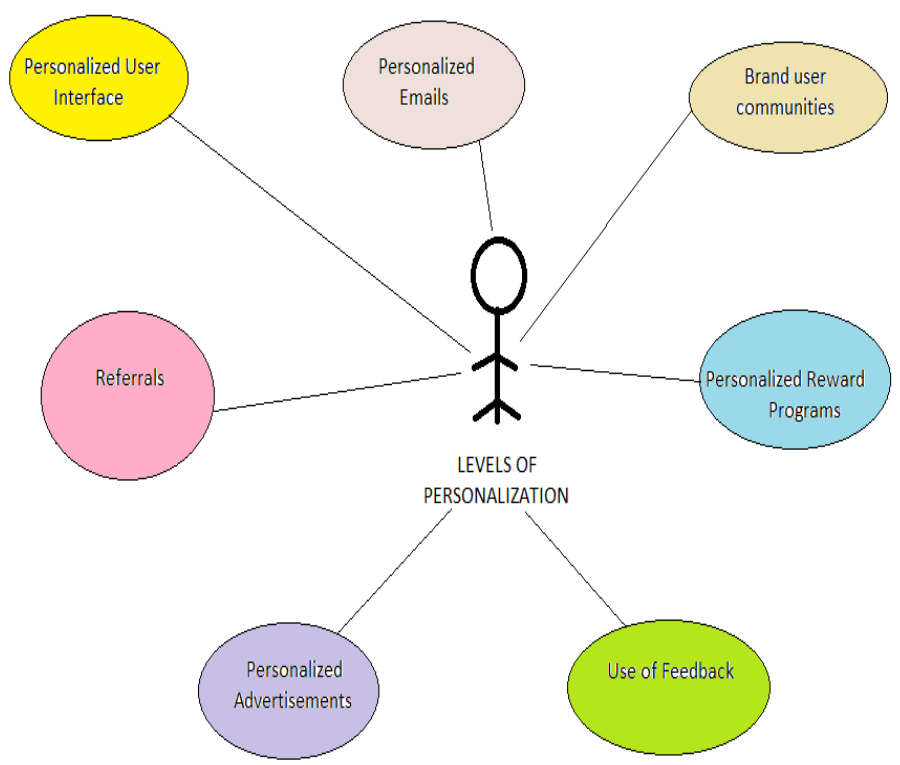

Fig I- Levels of Personalization 


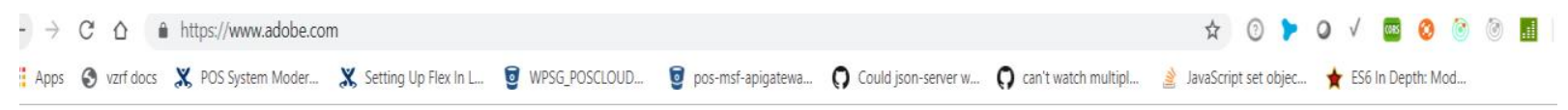
14) Adobe
Creativity \& Design
Marketing \& Commerce
PDF \& E-signatures
Business Solutions
Support
(0) Sign In

\section{Dream bigger. Creative Cloud.}

\section{The next generation of Creative Cloud is here. New apps. New features.} New ways to create. It's everything you need to go from dreaming to doing.

\section{Start free trial}

Learn more :

Fig II- Adobe Homepage

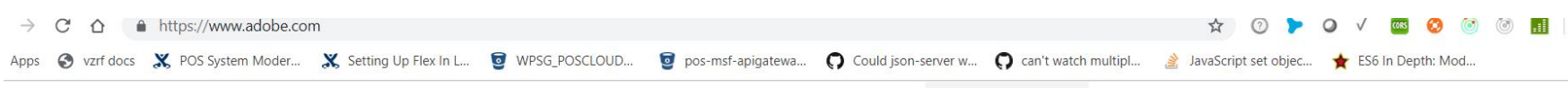

\section{(14) Adobe}

Creativity \& Design

Marketing \& Commerce

PDF \& E-signatures

Business Solutions

Support

2. Sign In

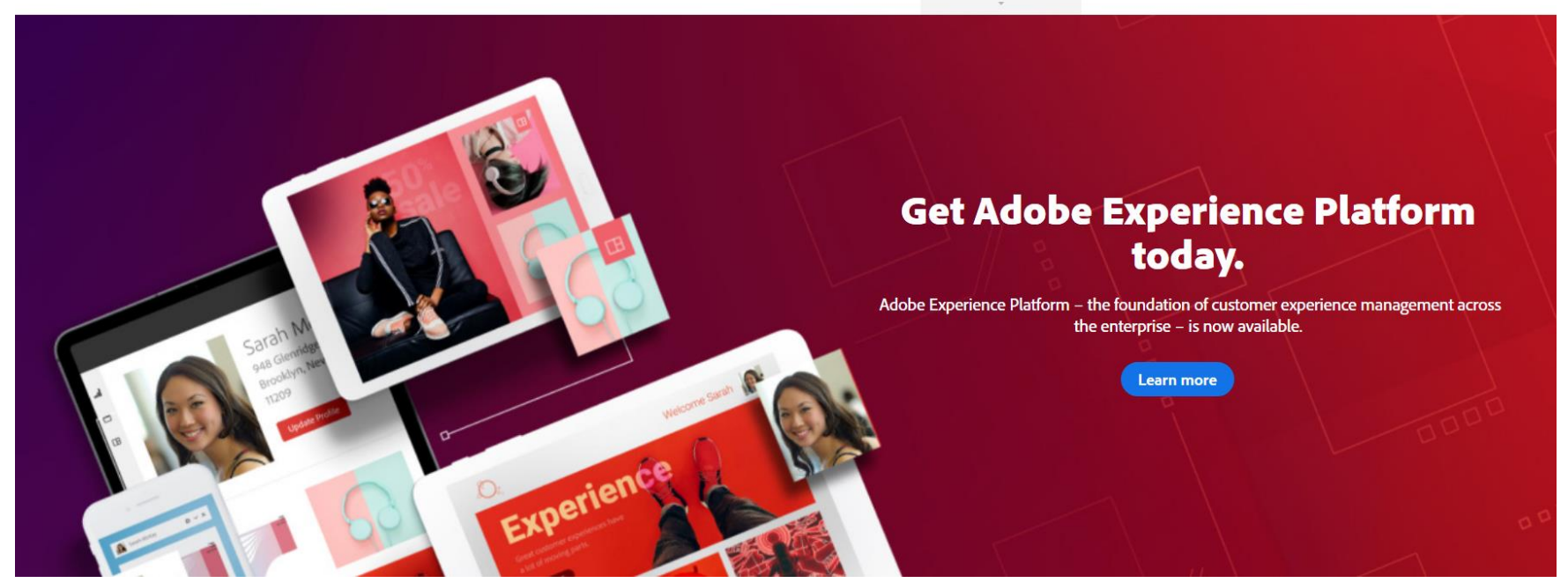

Fig III-Adobe Homepage Revisit 


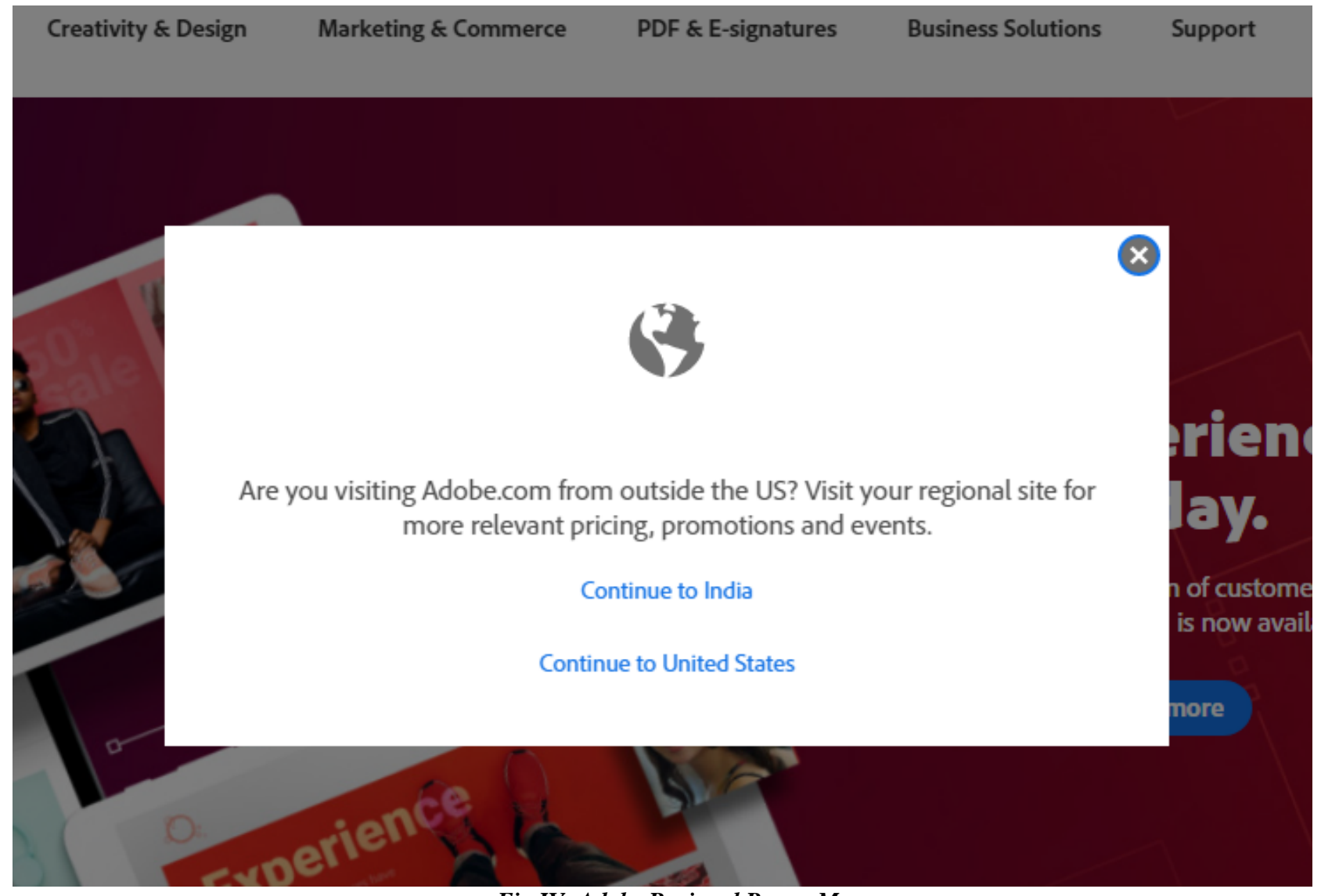

Fig IV-Adobe Regional Popup Message

\section{Welcome back}

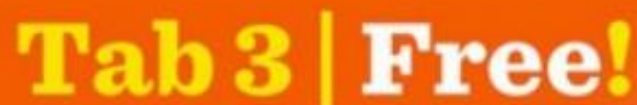

Online only: Already a customen? Sign in to

see if yourre ellgible to get the Samsung

Galaxy Tab $=3$ for FREEl

Sign in

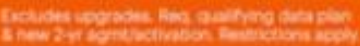

Follow us: fflike $<1,7 \mathrm{~m}$ Follow esprint
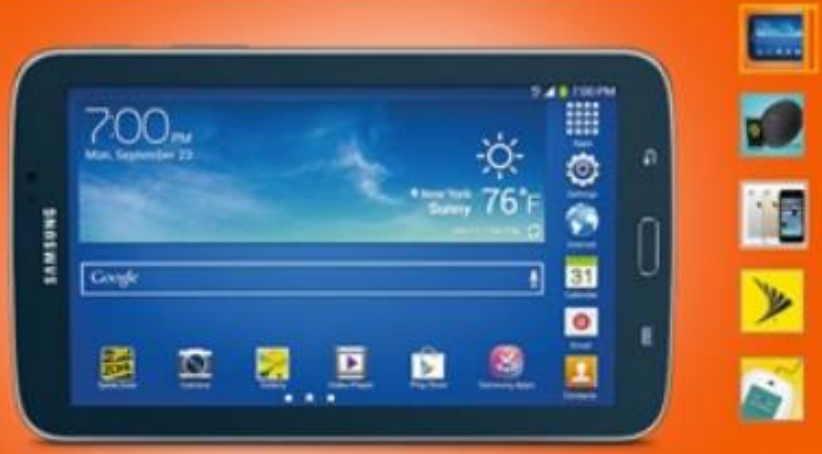

Fig V-Sprint old website with cookie based welcome back message 


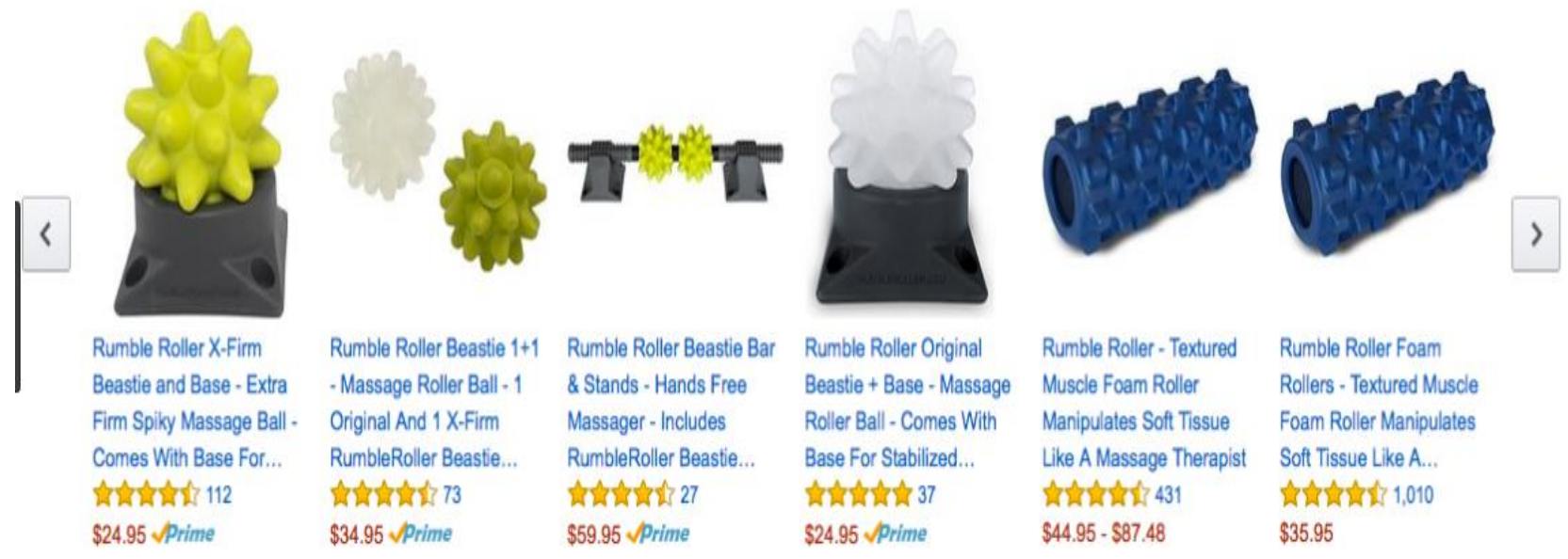

Fig VI- Amazon.com product recommendation

\section{o Continus Shopsing}

YOUR CART
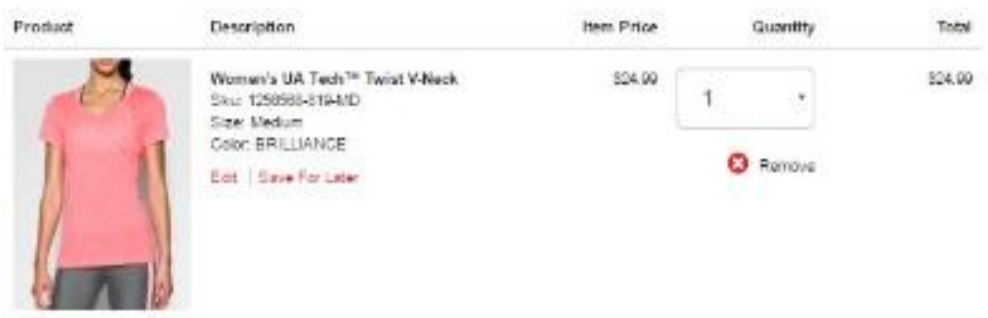

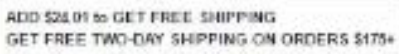

Subtotal $\$ 24.99$

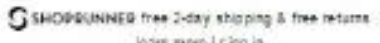
wart neas i seais

\section{SETUFN POUCY} The stove bethet our poduces troes.

\section{CUSTOMERS ALSO BOUGHT}
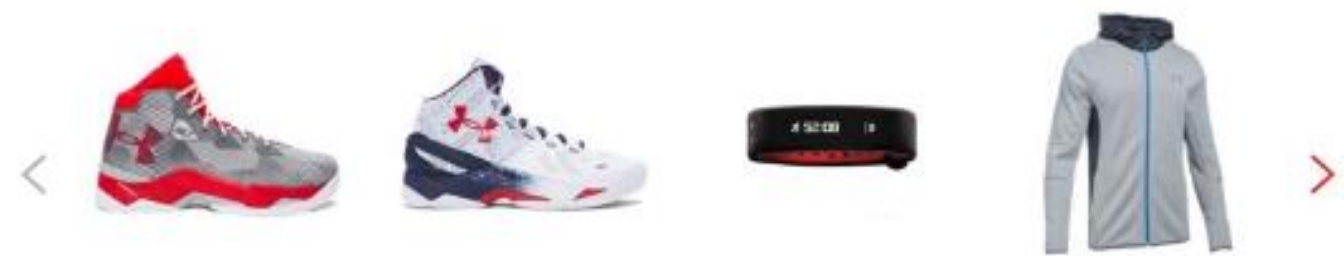

Fig VII- Cross selling through 'customers also bought' 

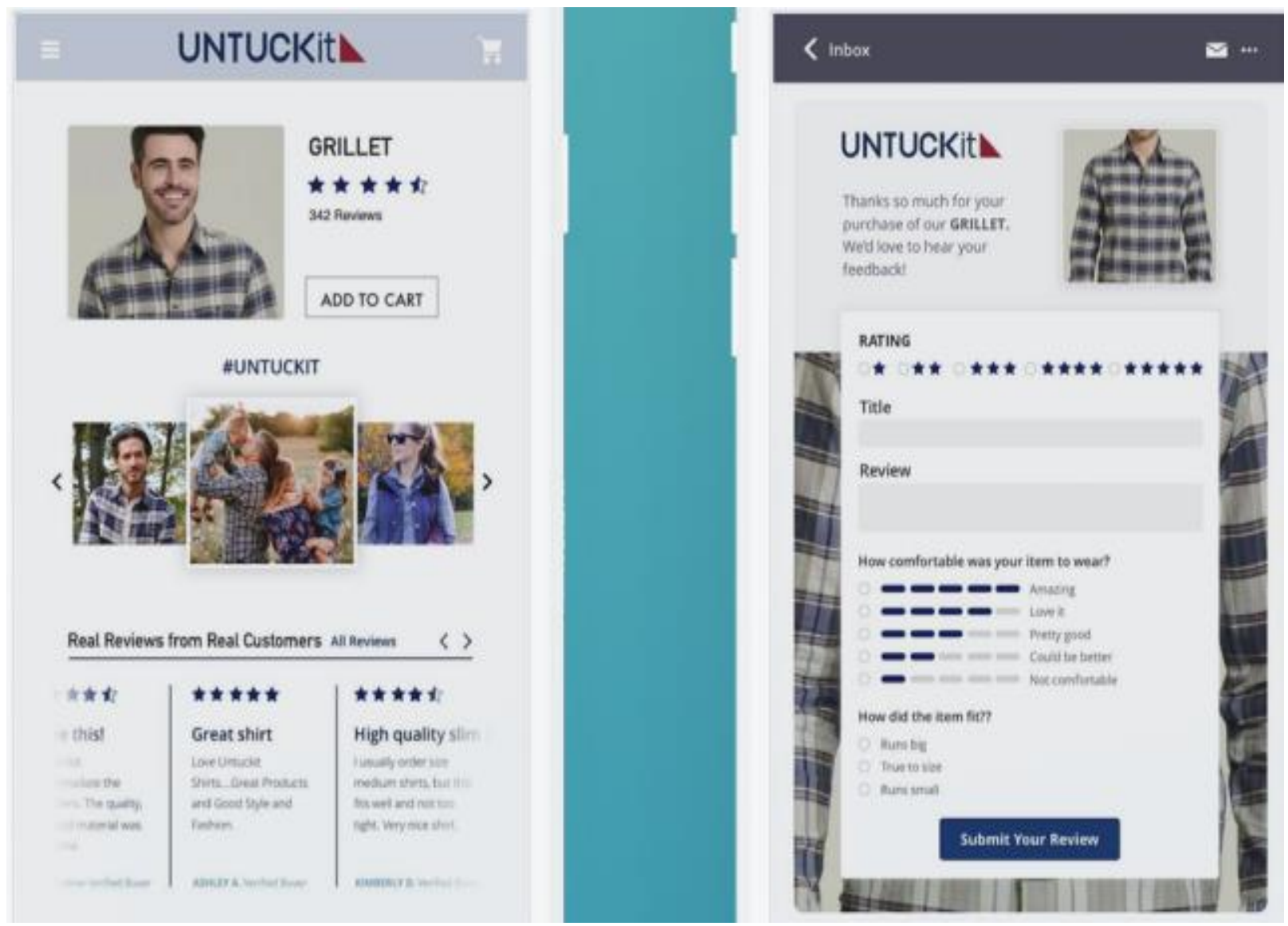

Fig VIII- UNTUCKit product display page (Source: Nosto.com)

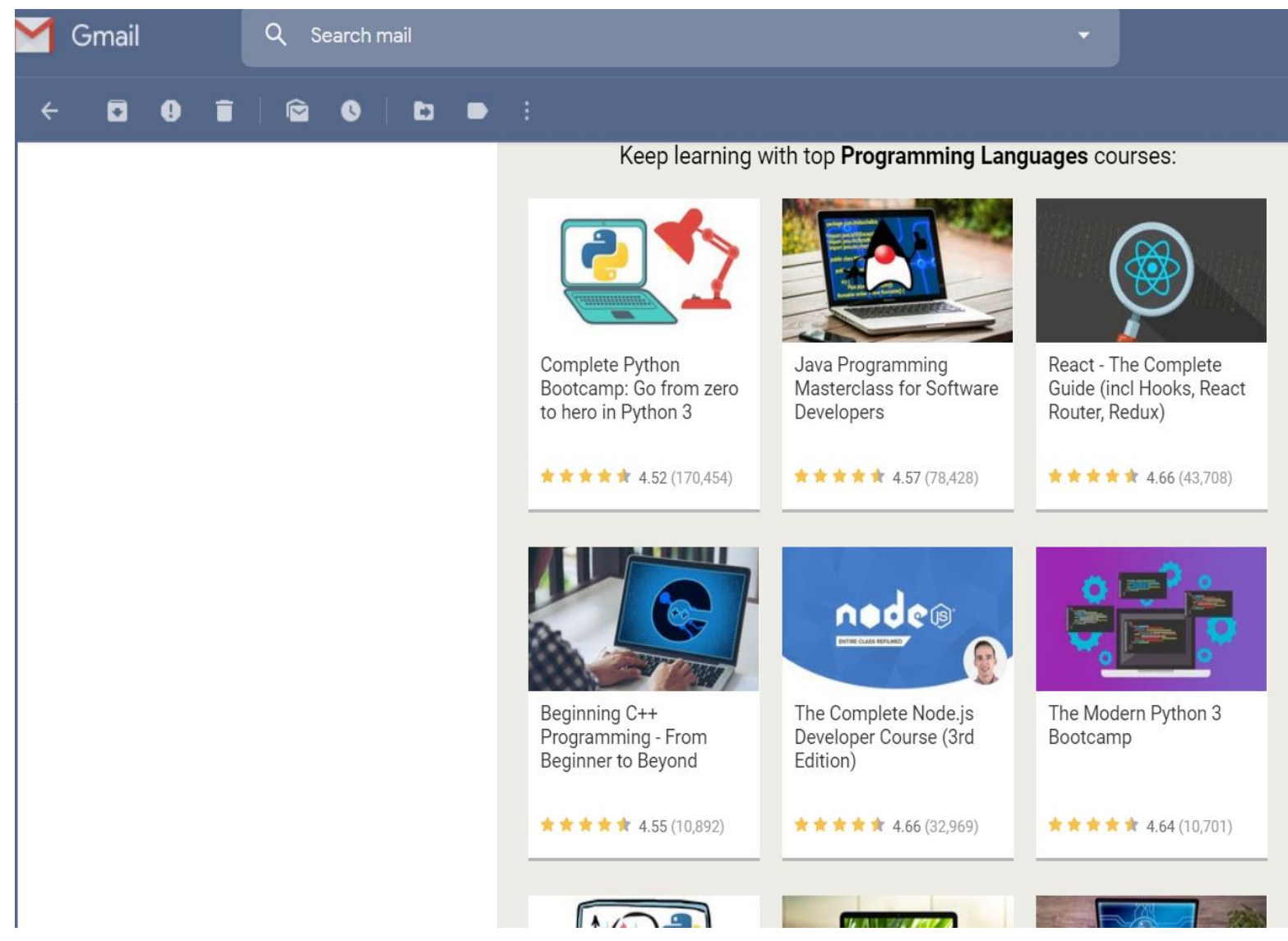

Fig IX-Udemy personalized emails 


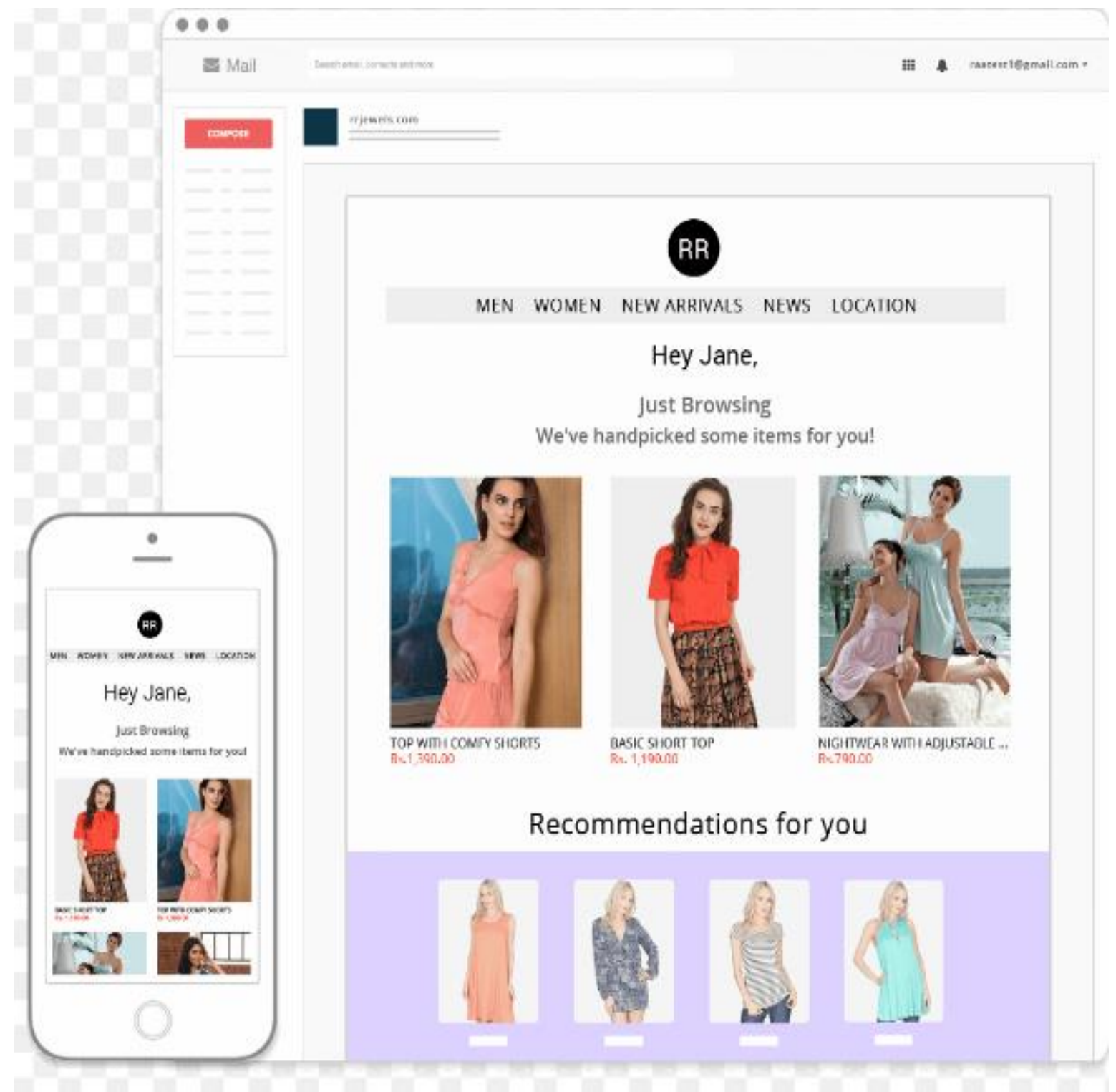

Fig X-Rrjewels email 


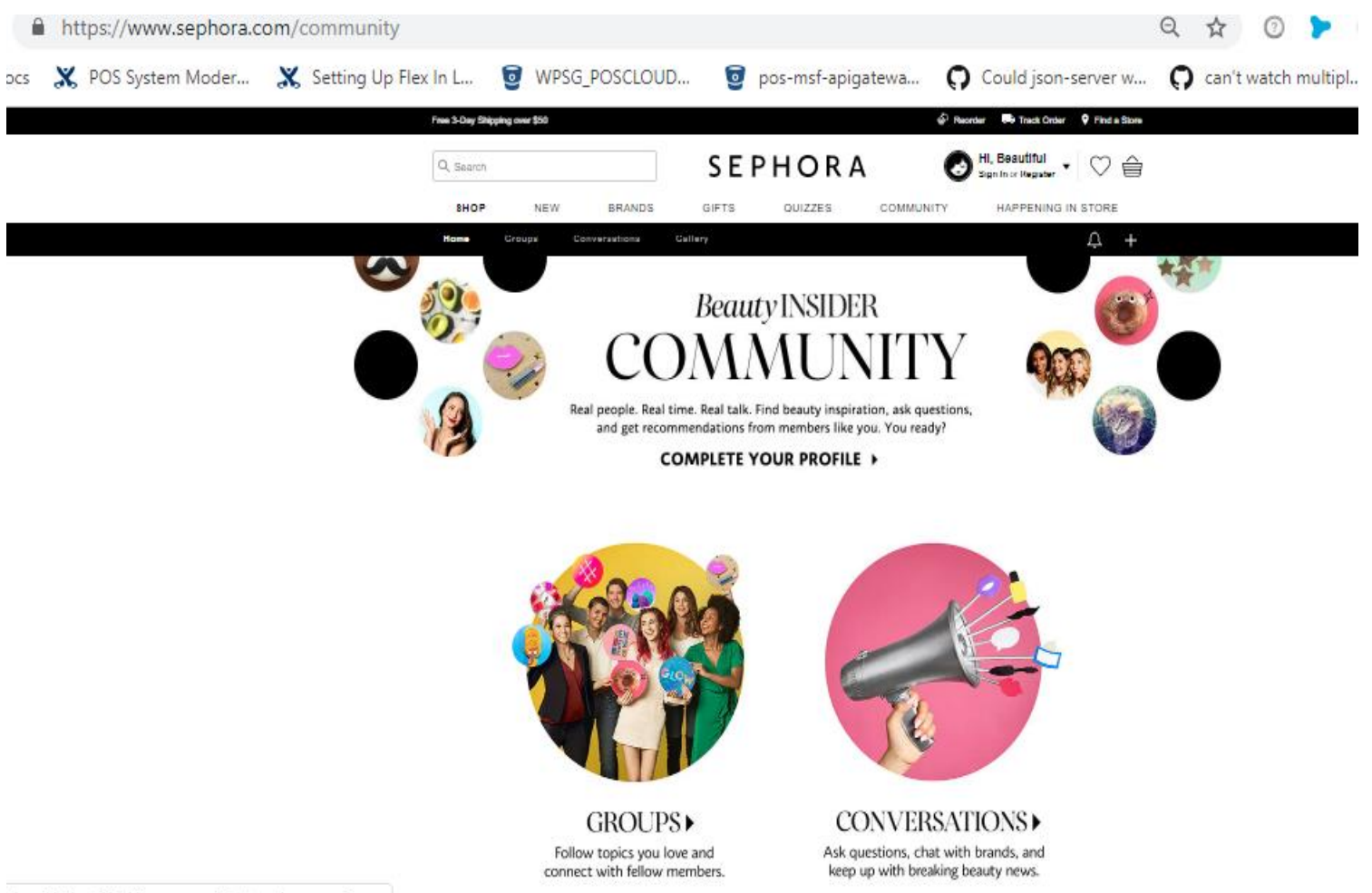

Fig XI- Sephora discussion forum

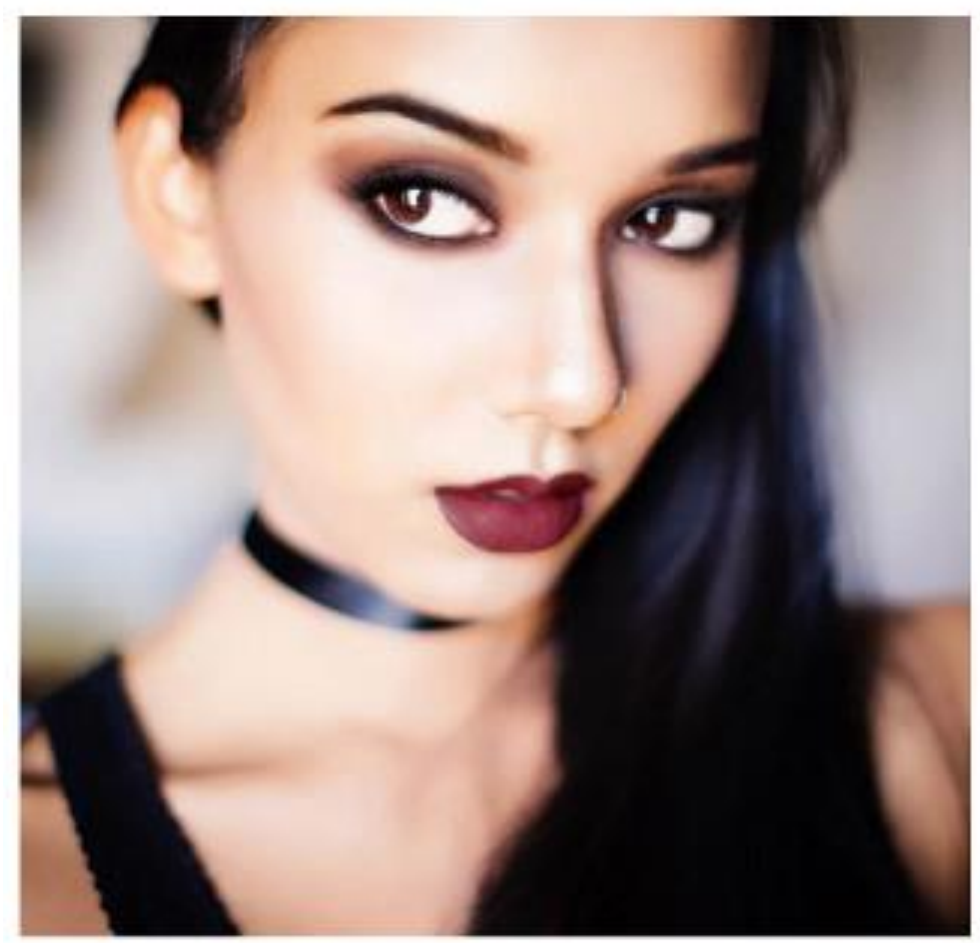

01

FEELIN VAMPY

Tharks for looknal ?

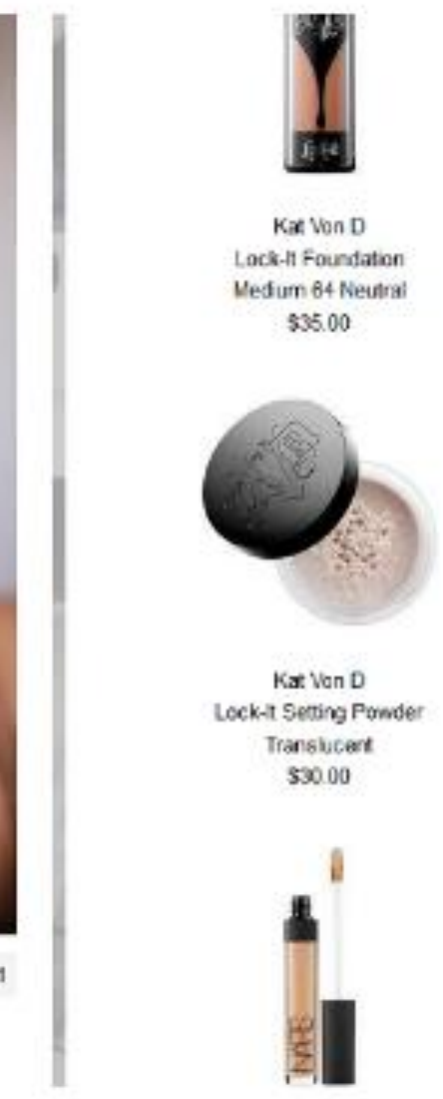

Fig XII-Sephora beauty board (Source: Nosto.com) 


\section{my sover

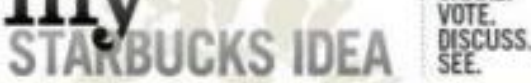

Share Your Idea I View All Ideas Ideas In Action About This Site

Welcome, Guest

Sign In

to share, vote

\& discuss

SicN IN

Check out

the latest

ideas now!

\section{Help shape the future of Starbucks - with your ideas}

You know better than anyone else what you want from Starbucks. So tell us. What's your Starbucks Idea? Revolutionary or simple-we want to hear it. Share your ideas, tell us what you think of other people's ideas and join the discussion. We're here, and we're ready to make ideas happen. Let's get started.

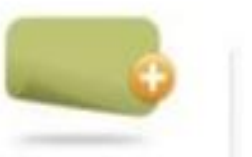

share

Pont vour Starbucies idea-from ways we could improve to things ve' men thoughe at.

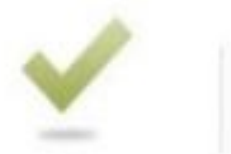

\section{vote}

Oneck out othet people's ideas and vote on the ones you

$$
\text { ille best. The }
$$
commusty votes. The communiry decides.

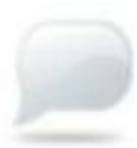

\section{discuss}

Tax abour ideas wim cener custamers and our Sarbucks life? Partureis and heip make perm rves better.

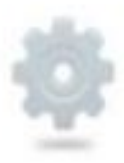

see

This is the prod, see which of your ideas were the moit oopular and watch a: we bake action

Fig XIII- My Starbucks Idea 


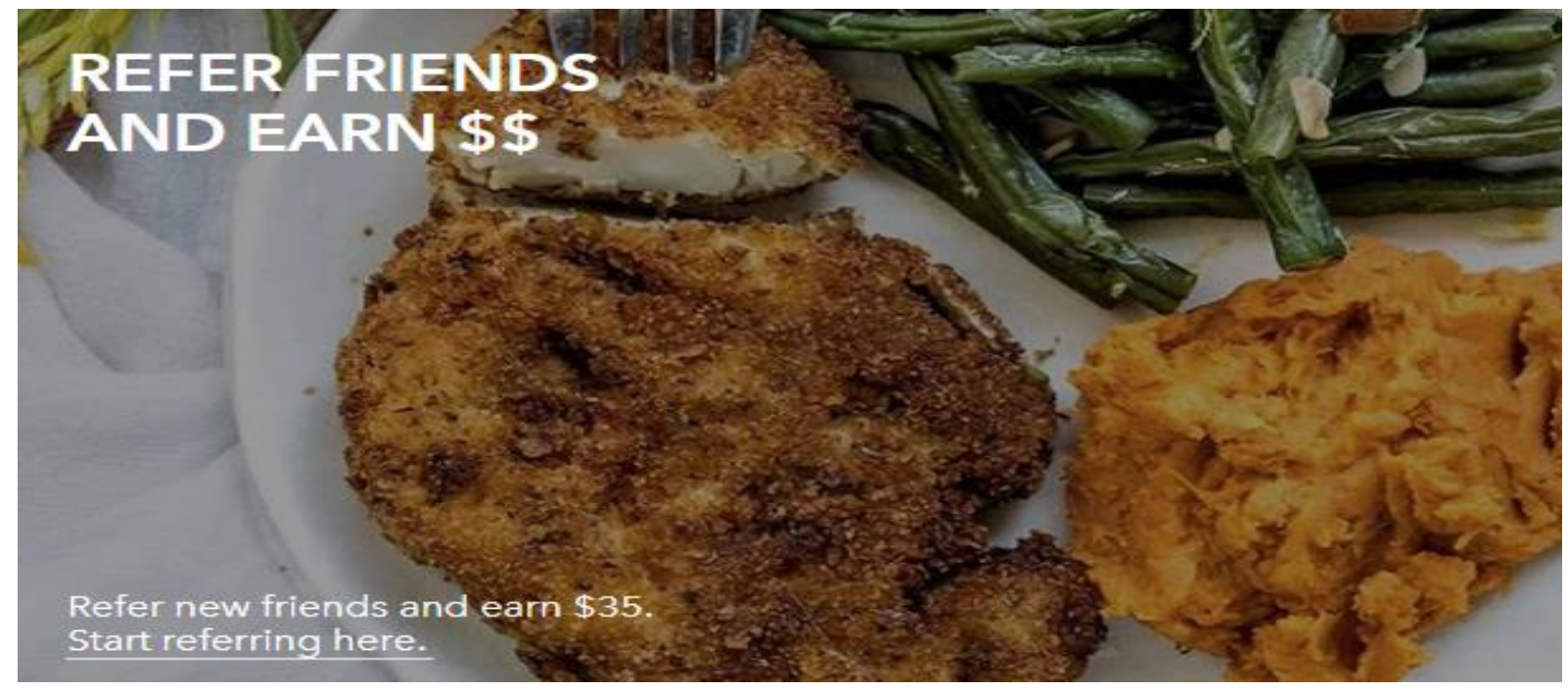

- https://www.veestro.com/pages/refer

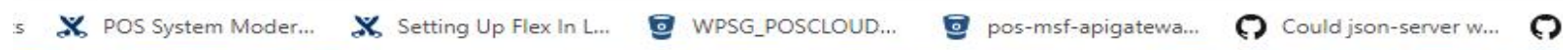

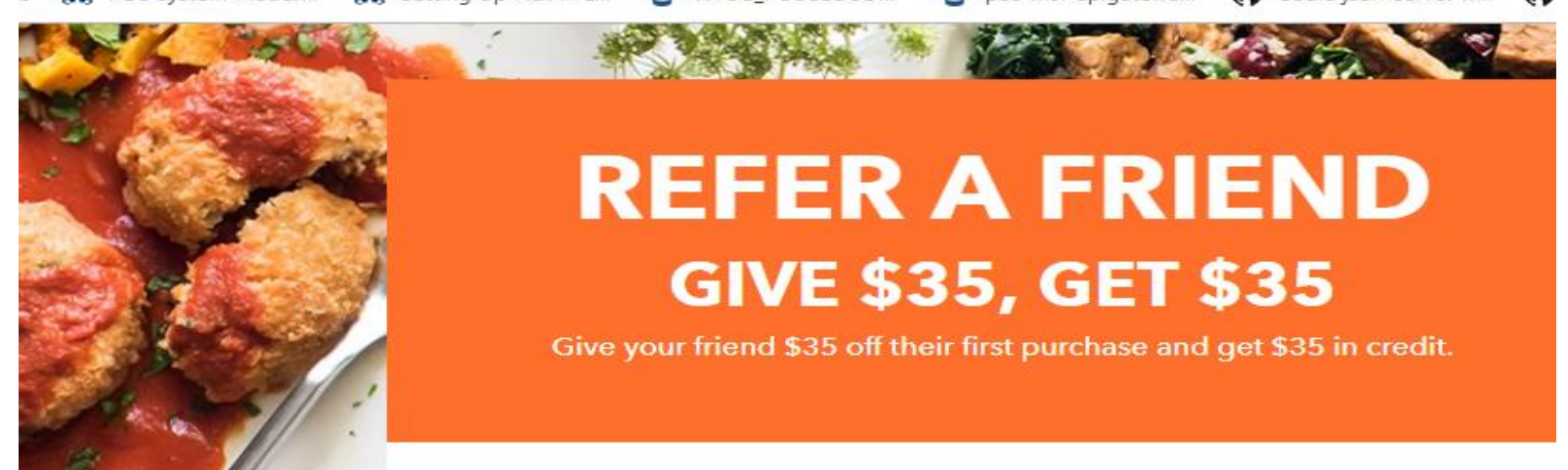

Please submit your email below to register.

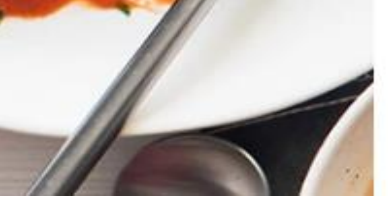

Fig XIV-Veestro refer a friend 


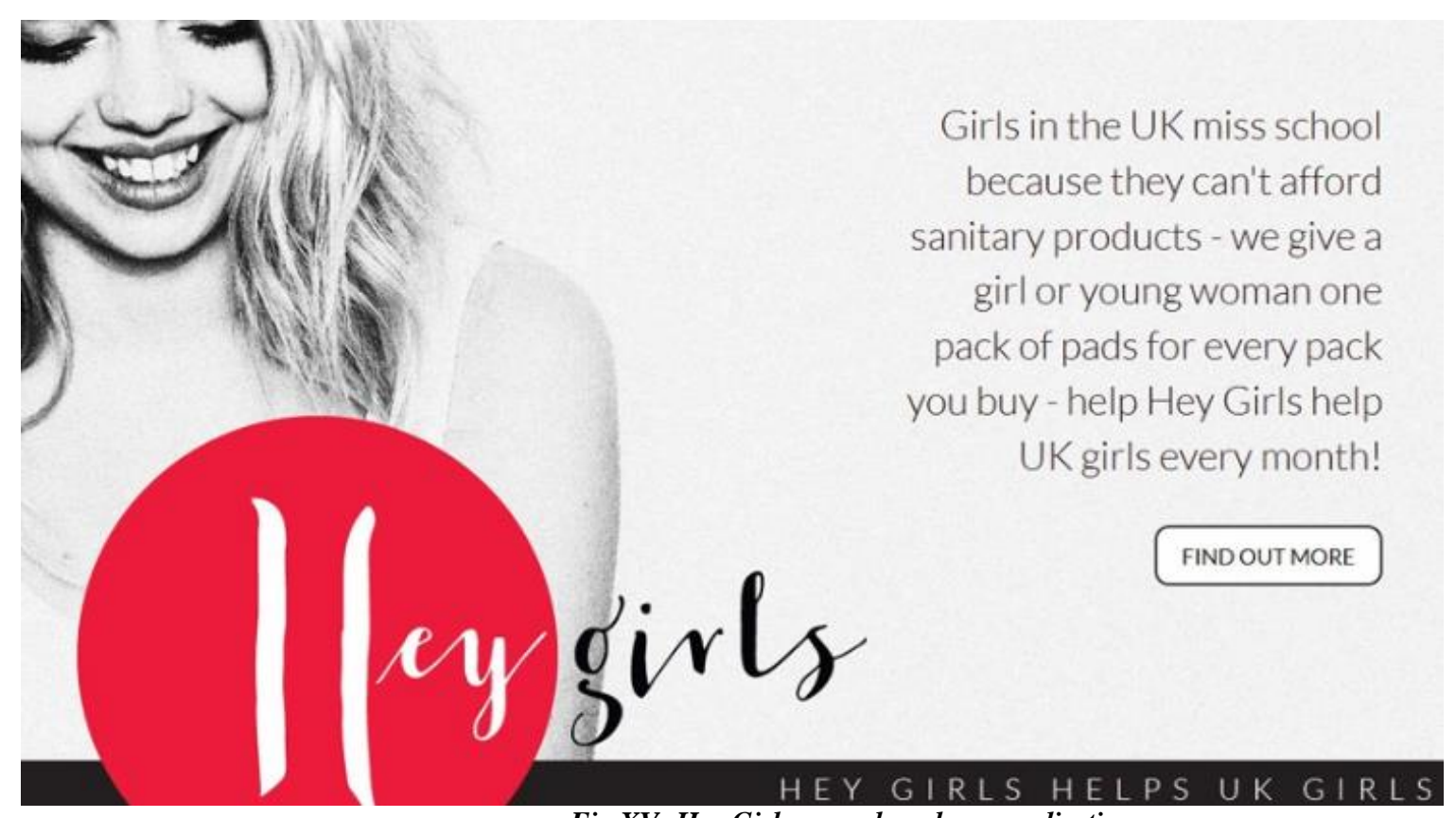

Fig XV-Hey Girls cause based personalization 
https://www.verizonwireless.com/military/

X POS System Moder... $\quad$ X Setting Up Flex In L...

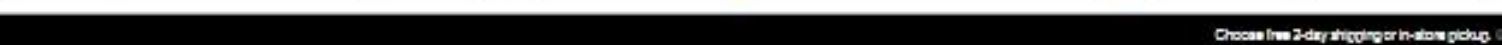

verizon

Wreten intars ganem

$\operatorname{sen}$ suse o a

phoren Plane Dewi shop supsort 96

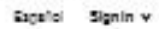

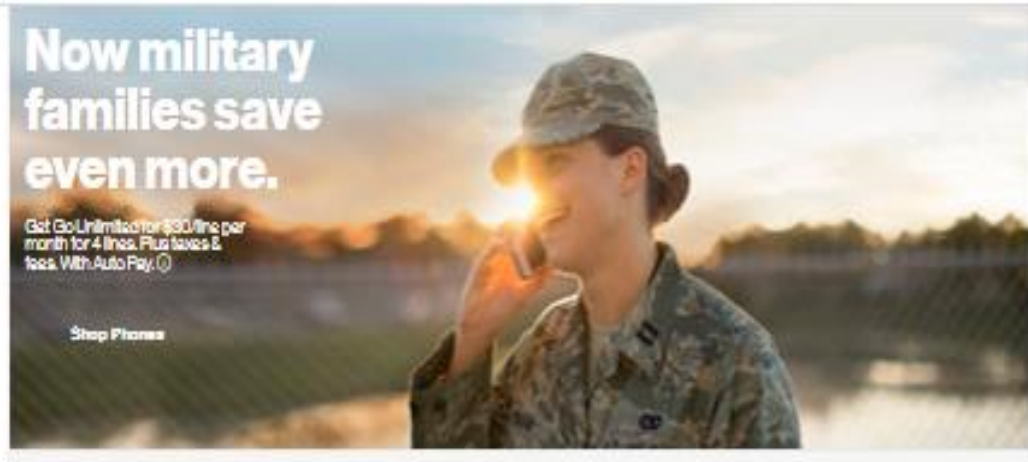

Wrolose Foe

Our thanks to

all who serve.

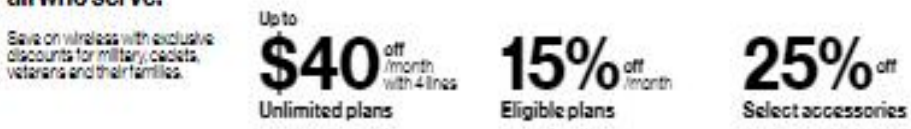

3enfongs

Enroll today to take advantage of your discount.

Verizonsupports the Wounded Warrior Project.

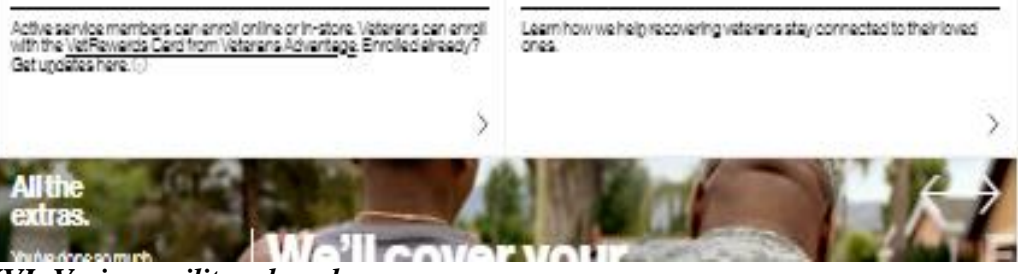

Fig XVI-Verizon military based cause 


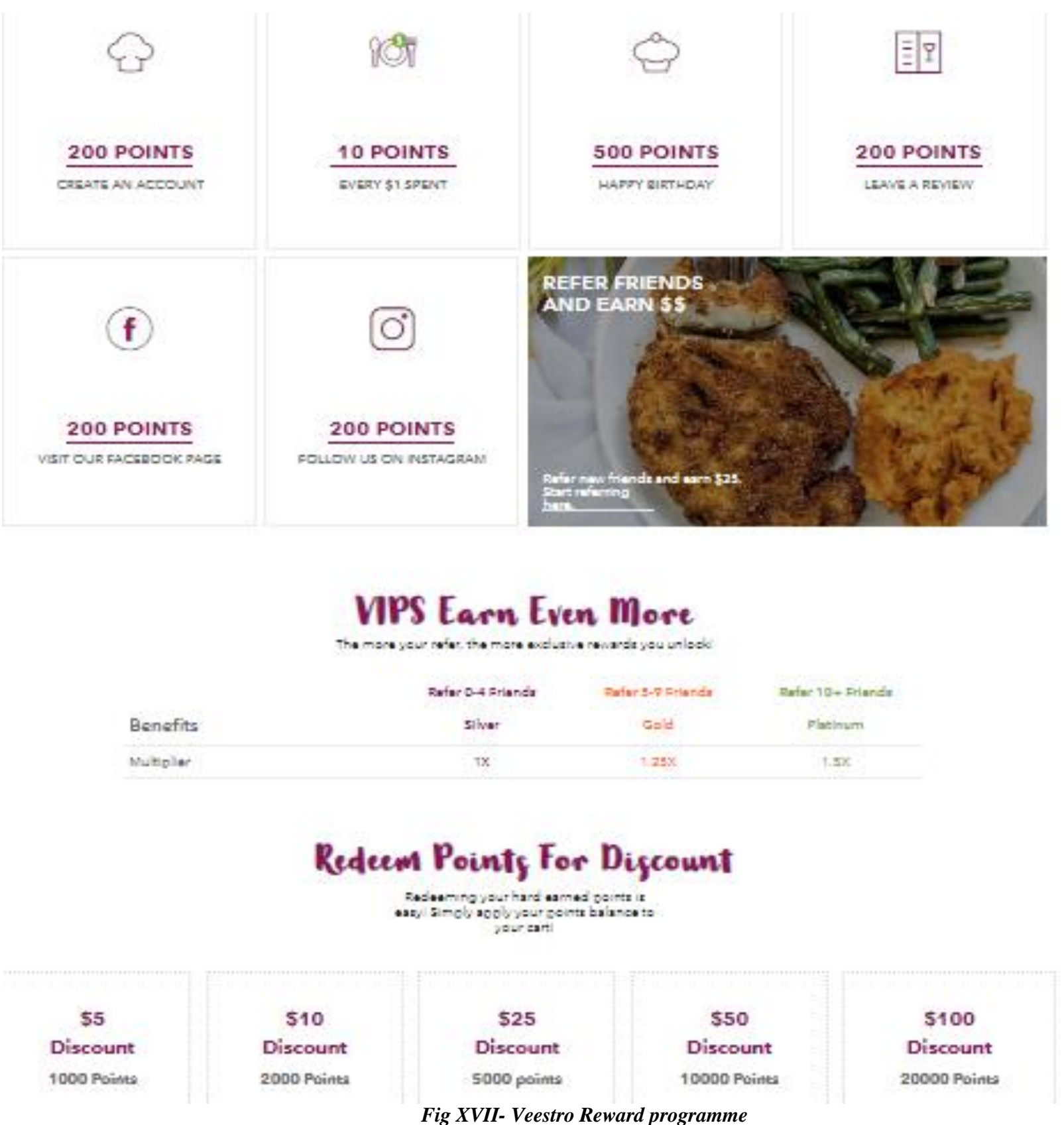

Fig XVII- Veestro Reward programme 


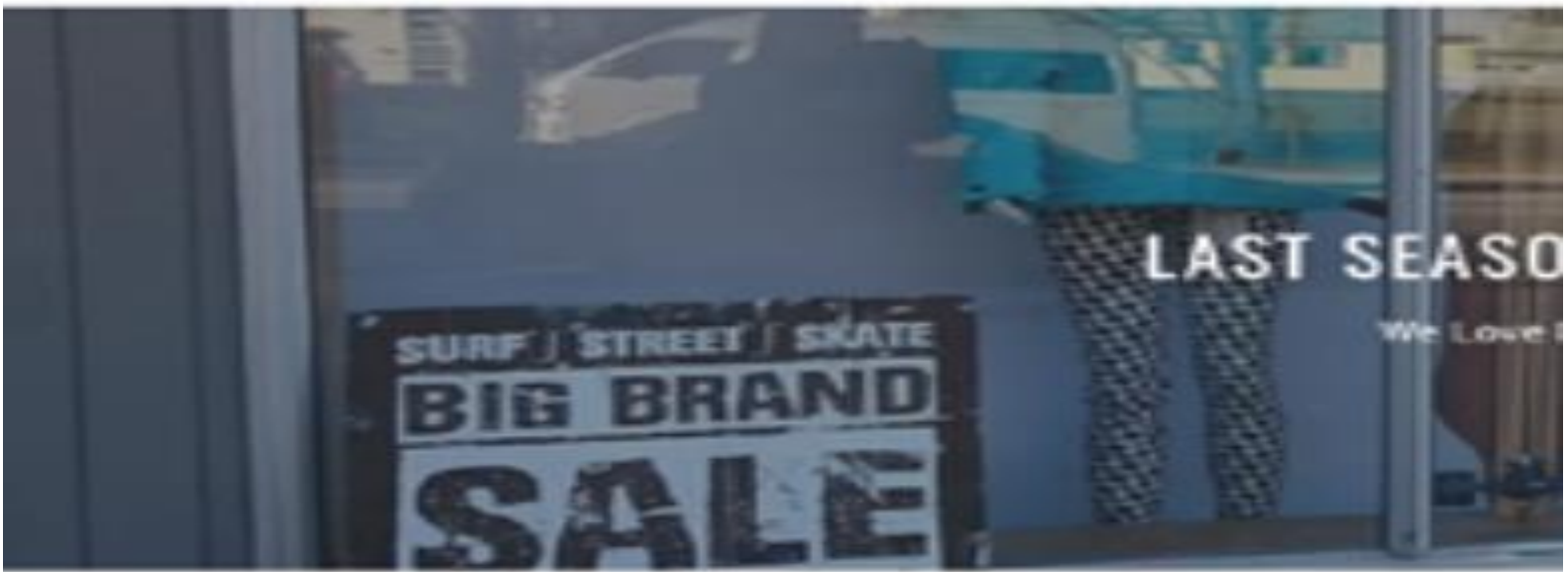

\section{COME ON DOWN:}

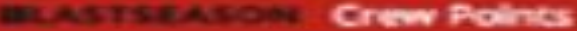 \\ to yecenstown for the winter to gine you t}

Fig XVIII- Last season reward program link on homepage

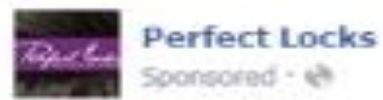

Upgrade your hair extensions. Voted $=1$ by stylists worldwide.

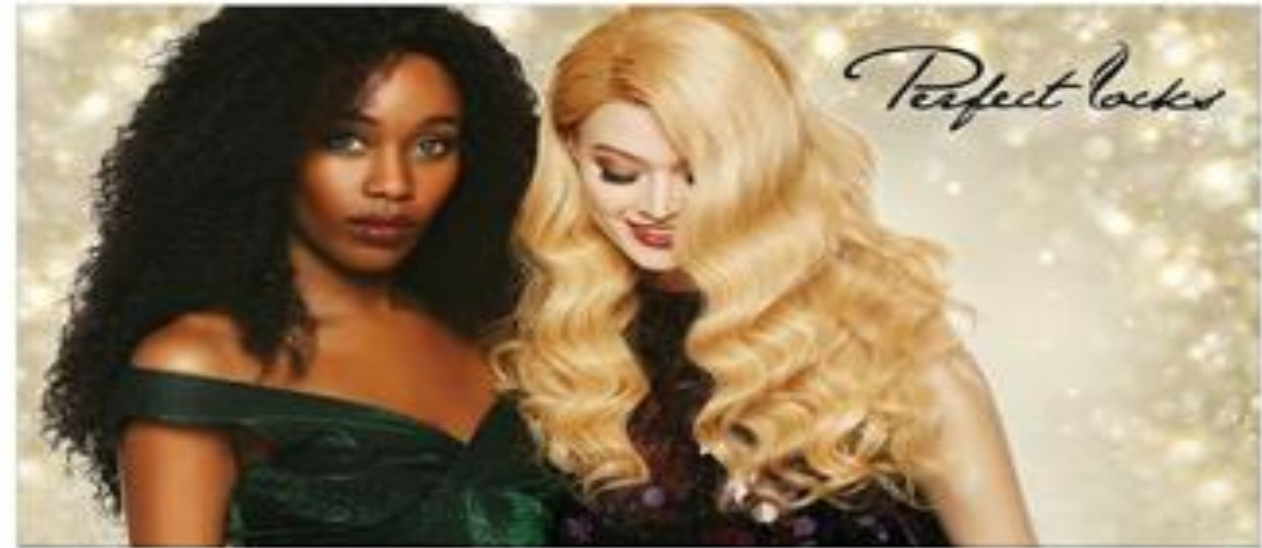

$\star \star \star \star \star$ "Customer for Years"

Karrah M: This is the best hair. It doesnt tangle at all, there is very minimal shedding, virtually none and you can reuse it for months with proper care. My schedule is beyond hectic and I Eice maintenance free hair and Perfect Locks.

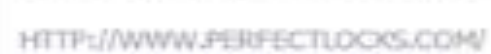

Shop Now

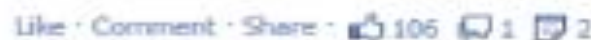

Fig XIX-PerfectLocks user generated content + star ratings advertisement 


\title{
Order Summary
}

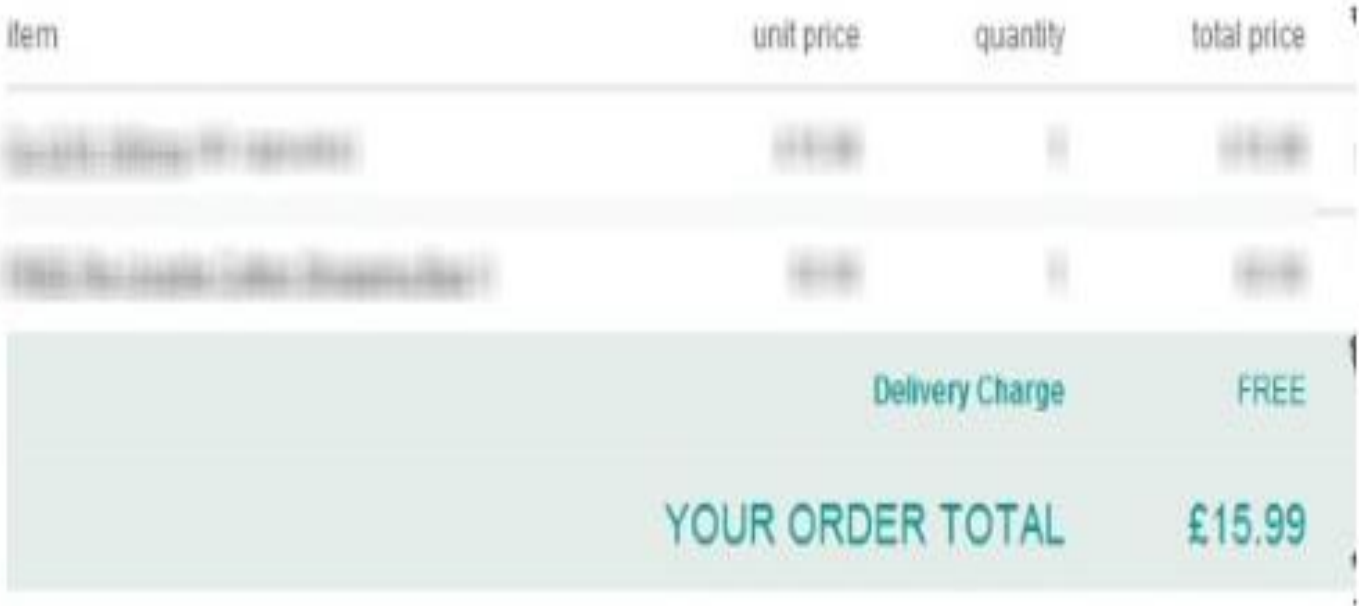

\section{Thank you for shopping with us. If you have a moment, we'd welcome some feedback.}

\section{Pease read through the following questions and rate us accordingy:}

Excelent Good far Weak Poor

\author{
How easy was t to find what you wanted? \\ How would you rate the variety of products avaiable from us? \\ Overal, how would you rate your experience shopping on
}

2. How lkely are you to recommend us to others?

Very Lkely Somewhat Lkety Nether likey or unikely Somewhat unikey Very unikely

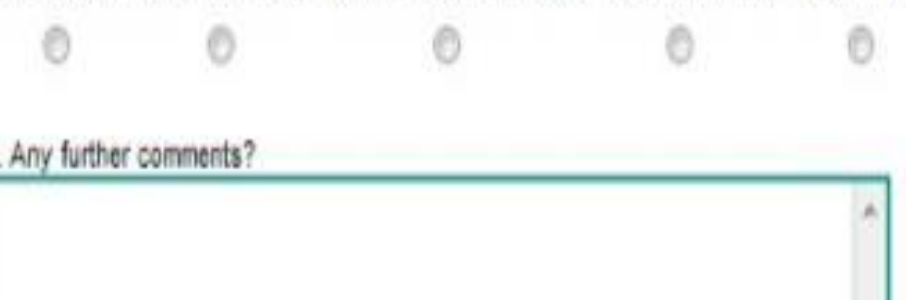

Fig XX-Feedback form on order completion screen 


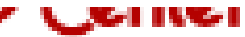

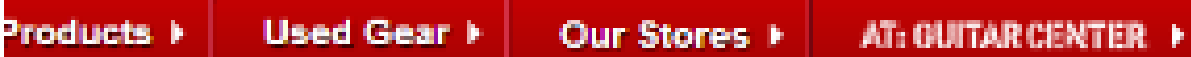

\section{nternational Checkout}

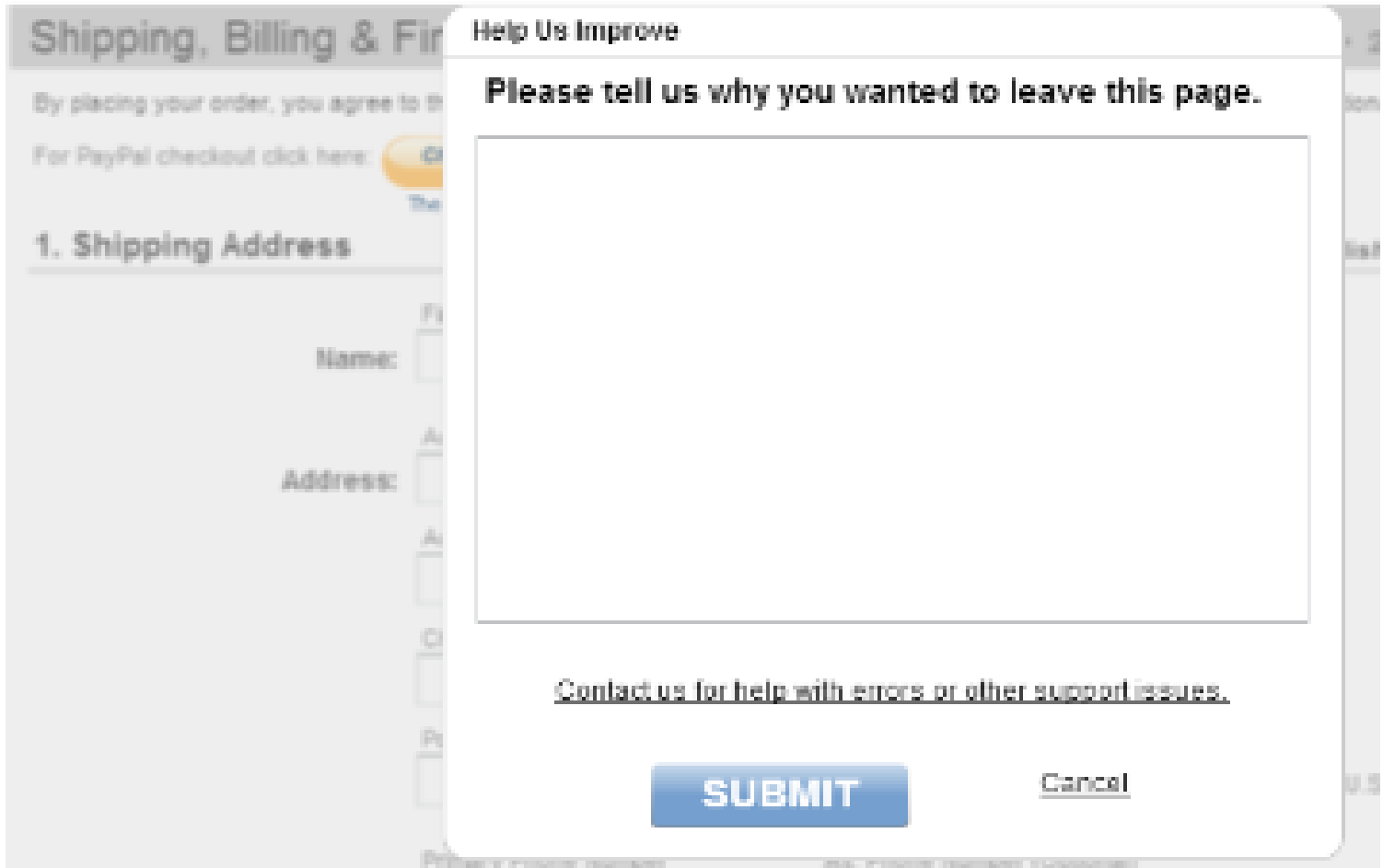

Fig XXI- Feedback form on leaving any page mid funnel

\section{1 i https//Www.sprintcom}

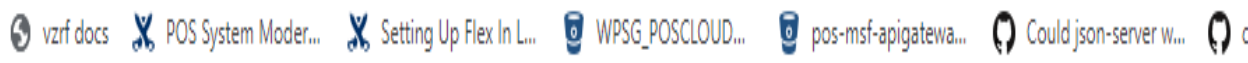
Esponiol | Business | Stores

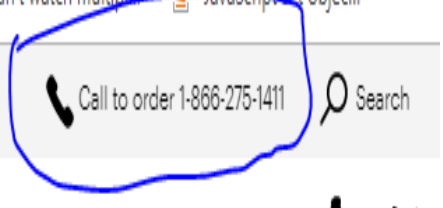

Shop Devices Shop Plans Support My Sprint Activate

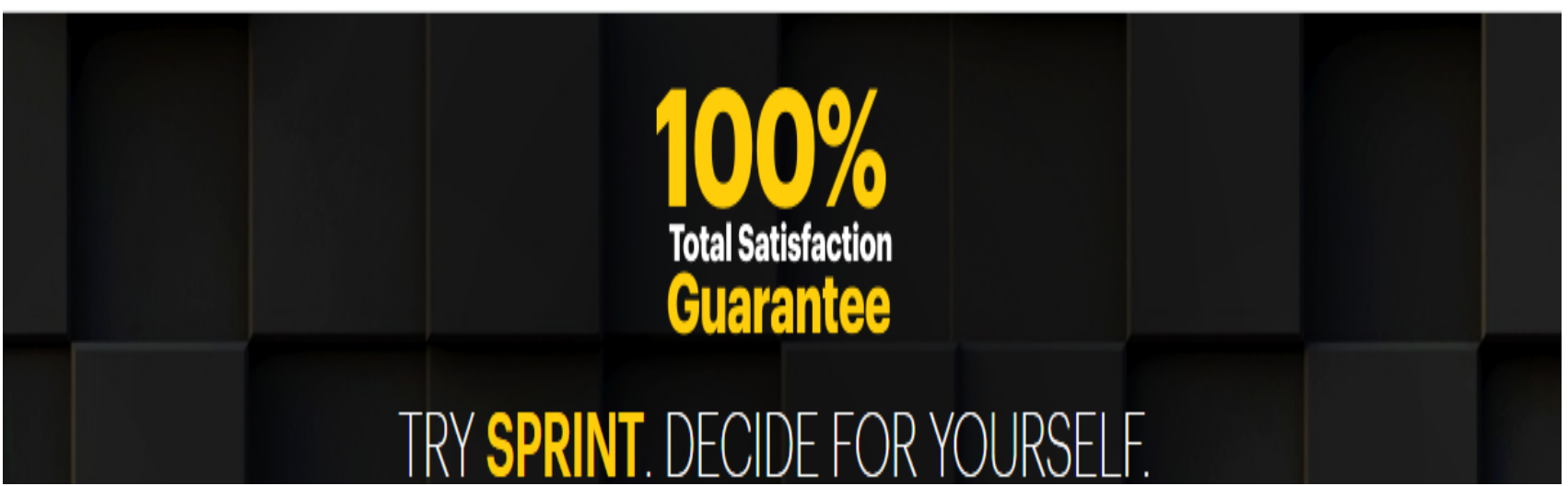

Fig XXII- Sprint contact number clearly given on homepage 


\section{Need It Sooner?}

\section{Buy Crilime, Piok LP In Store Learn More}

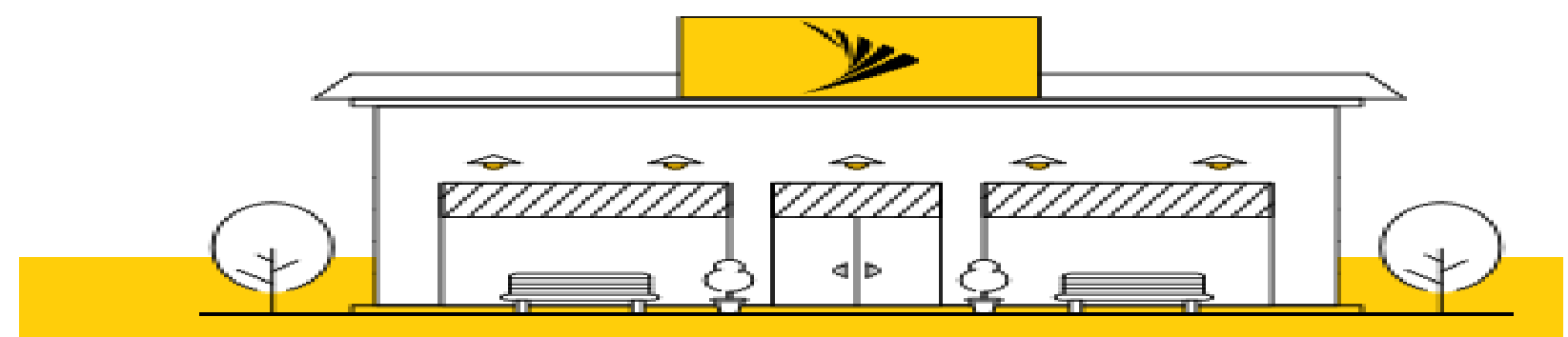

Fig XXIII- Sprint omni channel experience clearly given on homepage- online/store options 